\title{
The phonetic motivation for phonological stop assibilation*
}

\author{
T. A. Hall \\ Indiana University
}

Silke Hamann

Zentrum für Allgemeine Sprachwissenschaft, Berlin

Marzena Żygis

Zentrum für Allgemeine Sprachwissenschaft, Berlin

This article examines the motivation for phonological stop assibilations, e.g. $/ \mathrm{t} /$ is realized as [ts], [s] or [t $\left.\int\right]$ before $/ \mathrm{i} /$, from the phonetic perspective. Hall \& Hamann (2003) posit the following two implications: (a) Assibilation cannot be triggered by $/ \mathrm{i} /$ unless it is also triggered by $/ \mathrm{j} /$, and (b) Voiced stops cannot undergo assibilations unless voiceless ones do. In the following study we present the results of three acoustic experiments with native speakers of German and Polish which support implications (a) and (b). In our experiments we measured the friction phase after the $/ \mathrm{t} d /$ release before the onset of the following high front vocoid for four speakers of German and Polish. We found that the friction phase for $/ \mathrm{t} \mathrm{j} /$ was significantly longer than that of $/ \mathrm{ti} /$, and that the friction phase of $/ \mathrm{t} / \mathrm{in}$ the assibilation context is significantly longer than that of $/ \mathrm{d} /$.

\section{Introduction}

This article examines stop assibilations - defined here as processes which convert a (coronal) stop to a sibilant affricate or fricative before high vocoids, e.g. /t/ is realized as [ts], [s] or [t $\left.\int\right]$ before /i/. In a typological study of phonological assibilations in more than 30 typologically diverse languages, Hall \& Hamann (2003) postulate the following two implications:

\footnotetext{
* We would like to thank Susanne Fuchs, Christine Mooshammer and Bernd PompinoMarschall for comments on an earlier version of this article. We are also grateful to the input provided by the audience of the $26^{\text {th }}$ DGfS Conference in Mainz and the $9^{\text {th }}$ Conference on Laboratory Phonology in Urbana-Champaign. All disclaimers apply.
} 
(1) Two implications:

a. Assibilation cannot be triggered by /i/ unless it is also triggered by $/ \mathrm{j} /$.

b. Voiced stops cannot undergo assibilations unless voiceless ones do.

In the present study we present the results of three acoustic experiments with native speakers of German and Polish which support the implications in (1). It will also be shown that additional results of these three experiments point to possible universal generalizations on phonological assibilations not discussed in the literature on this process (e.g. Clements 1999, Kim 2001, Hall \& Hamann 2003). The present treatment is therefore important because we provide additional evidence that phonological assibilations can only be adequately explained by appealing to phonetics (see the authors cited above).

The purpose of this paper is to consider implications like the ones in (1) from the phonetic perspective. In particular, since stop assibilation is a process which is phonetically motivated by the turbulent noise which occurs after the release of a stop into a following high vocoid (referred to below as the friction phase), we postulate that implication (1a) can be supported if it can be shown that the friction phase in $/ \mathrm{tj} \mathrm{dj} /$ is significantly longer than in $/ \mathrm{ti} \mathrm{di} /$. The implication in (1b) would similarly derive support if the friction phase in sequences like /ti/ is longer than in /di/. We would furthermore expect that these predictions could be borne out in any one of a number of languages, since Kim's (2001) universal claims are based on a phonetic study of a single language (Korean) and Hall \& Hamann's (2003) observations hold for a number of typologically diverse languages. In the following paragraphs we present the results of an acoustic study of /ti tj di dj/ sequences in German and Polish.

This article is organized as follows. In $\S 2$ we define in greater detail the kind of processes we understand to be assibilations and summarize briefly the typological findings in Hall \& Hamann (2003) which led them to posit the two implications in (1). $\S 3$ summarizes two predictions pertaining to the phonetic realization of sequences like /ti/, /di/, /tj/ and /dj/ which - if confirmed - would support the two implications in (1). In $\S 4$ we present the results of three acoustic studies in which the friction phase from the release of $/ \mathrm{t} d /$ onto a following high vocoid for several German and Polish speakers is measured. The results of these experiments are significant because they lend support to the two predictions established in $\S 3$. In $\S 5$ we discuss several unexpected factors influencing the friction phase in sequences like/ti/, namely the relevance of stress and quality of the adjacent vowels. In $\S 6$ we discuss the phonetic motivation of the results of the three experiments, namely the reason why $/ \mathrm{j} /$ triggers a longer friction phase in a preceding stop than $/ \mathrm{i} /$ (section 6.1), the motivation for a longer friction phase in /t/ than in /d/ (section 6.2), the influence of stress (section 6.3) and the influence of the quality of adjacent vowels (section 6.4). $\$ 7$ considers an 
alternative phonetic motivation for implications in (1), namely the similarity in center of gravity of burst friction before $/ \mathrm{i} /$ and $/ \mathrm{j} /$ for both alveolar stops. $\S 8$ concludes.

\section{Stop assibilations}

In this section we define what we mean by stop assibilation and then present several universal properties for such processes discussed by Hall \& Hamann 2003, as well as by earlier authors, namely Foley (1973, 1977), Jäger (1978), Bhat (1978), Ohala (1983), Clements (1999) and Kim (2001).

Stop assibilations (or assibilations for short) are defined here as processes whereby stops become sibilant affricates or sibilant fricatives before high vocoids. Three examples of such rules have been presented in (2).

(2) Three examples of phonological assibilation rules:
a. $\mathrm{t} \rightarrow \mathrm{s} / \mathrm{i}$
Finnish (Kiparsky 1973)
spirantization
b. $\mathrm{t} \mathrm{t}^{\mathrm{h}} \rightarrow \mathrm{ts} \mathrm{ts}^{\mathrm{h}} / \mathrm{i}_{1}$
Korean (Kim 2001)
affrication
c. $\mathrm{t} \rightarrow \mathrm{t} \int /$
West Futuna-Aniwa (Dougherty 1983)
posteriorization

The distinction between the three outputs in (2), i.e. 'spirantizations', 'affrications' and 'posteriorizations', is not important for the present study. The three processes are referred to collectively as assibilations because they all display a similar cluster of properties (see 3 below).

Although processes like the ones in (2) can also affect a velar stop (e.g. in Late Latin $/ \mathrm{k} \mathrm{g} /$ surfaced as [ts dz] before $/ \mathrm{j} /$; Pope 1952) and in some rare languages a labial (e.g. in Lahu labial stops and nasals are affricated before /u/; Mattisoff 1982: 3), we restrict our discussion to assibilations which have a coronal stop as the input segment, in particular the input is dental or alveolar, i.e. [+coronal, +anterior] in terms of distinctive features.

Assibilations like the ones in (2) can either be lexical or postlexical rules. For example, in Korean (see 2b) assibilation is lexical because it is restricted to applying within a derived environment and does not affect tautomorphemic /ti/, $/ \mathrm{t}^{\mathrm{h}} \mathrm{i} /$ sequences. In Quebec French (Cedegren, Archambault \& Boulianne 1991, Kim 2001) the assibilation rule is postlexical because it applies across the board, both within and across words. Since the properties we discuss below hold for postlexical and lexical assibilations we do not see the need to distinguish between the two rule domains.

The term 'assibilation' is used here in a very narrow sense since we restrict our discussion below to processes like the ones in (2), which share the following three properties (based on the findings of Clements 1999 and Kim 2001): 
(3) Three properties of stop assibilations:

a. the trigger is some subset of the high front vocoids (i.e. / $\mathrm{j} /$ )

b. the output is a sibilant (either an affricate or a fricative)

c. the trigger is to the right of the target

Earlier literature offers a phonetic explanation for the properties of stop assibilation in (3a-c). Jäger (1978: 316) states that "if a language has rules that either devoice, aspirate, fricate or affricate consonants before only some vowels but not others, it will be before high rather than low vowels." Jäger attributes this implication to the fact that the narrow constriction for high vowels creates better conditions for turbulence, which can affect the preceding consonant by adding frication to it. This frication together with the preceding stop can be reinterpreted as a fricated stop, i.e. an affricate. Ohala (1983: 204) also observes that stops tend to be realized with a fricated release when they are followed by close vowels. He ascribes this tendency to the fact that the high velocity of the airflow created upon release is maintained longer when a stop is followed by a close vowel as opposed to an open vowel. Kim (2001) and Clements (1999) state that the creation of sibilants from stops has its phonetic origin in the brief period of turbulence (or 'friction phase') which occurs at the release of a stop into a following high vocoid. Thus, Clements (1999) and Kim (2001) observe that the friction phase that occurs in some languages following the release of an alveolar stop into a high front vocoid is significantly longer than the friction phase of the same stop which is released into a non-high and/or non-front vocoid.

In Hall \& Hamann's (2003) study not all logical language types are shown to be attested. In (4) the ten logical language types are presented with the variables $/ \mathrm{i} /$ and $/ \mathrm{j} /$ as triggers and $/ \mathrm{t} /$ and $/ \mathrm{d} /$ as assibilating segments. Of these ten types only the five in (4a) were shown to be occurring.

(4) Ten logical language types:

a. Occurring assibilation types:

Language Type assibilating segment(s)
A

B

C

$\mathrm{D}$

$\mathrm{E}$
$/ \mathrm{t} \mathrm{d} /$

$/ \mathrm{td} /$

$/ \mathrm{t} /$

$/ \mathrm{t} /$

none

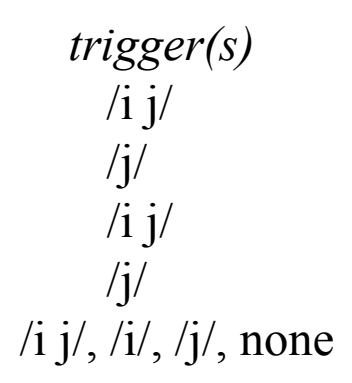

b. Nonoccurring assibilation types:

Language Type

assibilating segment(s)

$/ \mathrm{t} \mathrm{d} /$

$\operatorname{trigger}(s)$
$/ \mathrm{i} /$
/i/ 


$\begin{array}{lll}\mathrm{H} & / \mathrm{d} / & / \mathrm{ij} / \\ \mathrm{I} & / \mathrm{d} / & / \mathrm{j} / \\ \mathrm{J} & / \mathrm{d} / & / \mathrm{i} /\end{array}$

Hall \& Hamann (2003) propose that the nonoccurring language types in (4b) fall out from the two implications in (1) which we have repeated in (5) for convenience:

(5) Two implications:

a. Assibilation cannot be triggered by $/ \mathrm{i} /$ unless it is also triggered by $/ \mathrm{j} /$.

b. Voiced stops cannot undergo assibilations unless voiceless ones do.

Given the two triggers $/ \mathrm{i} /$ and $/ \mathrm{j} /$ and the two input segments $/ \mathrm{t} /$ and $/ \mathrm{d} /$, the implications in (5a-b) mean that none of the languages in (4b) is expected to occur.

\section{$3 \quad$ Predictions}

Since assibilations have their phonetic origin in the friction phase which arises after the release of a coronal stop before a high vocoid, we argue that the implications in (5) and the typology in (4) can be shown to be grounded in phonetics if the four predictions in (6) are borne out:

(6) Four predictions:

a. The friction phase in $/ \mathrm{tj} /$ is of longer duration than in $/ \mathrm{t} \mathrm{i} /$

b. The friction phase in $/ \mathrm{dj} /$ is of longer duration than in $/ \mathrm{di} /$

c. The friction phase in $/ \mathrm{tj} /$ is of longer duration than in $/ \mathrm{dj} /$

$\mathrm{d}$. The friction phase in /ti/ is of longer duration than in /di/

In essence, a longer friction duration after a coronal stop is more likely to be interpreted as affricate than a shorter one. If prediction (6a-b) can be shown to be correct then this finding would lend support to implication (5a). Along the same lines, if prediction (6c-d) can be substantiated experimentally then this would support implication (5b). ${ }^{1}$

The typology in (4) suggests an assibilation hierarchy as in (7), in which the wedge ' $<$ ' means 'implies'; hence, the assibilation of $/ \mathrm{ti} /$ implies the assibilation of $/ \mathrm{tj} /$, etc. Note that this typology makes no predictions concerning

Predictions (6c-d) can probably be attributed to the fact that the friction phase of $/ \mathrm{t} /$ is generally speaking longer than the friction phase in /d/ (regardless of the quality of the following vocalic element). See section 6.2 for discussion. 
the relationship of /ti/ to /dj/; hence, both sequences occupy the same slot in the hierarchy in (7).

(7) An assibilation hierarchy (to be revised):

$/ \mathrm{tj} /<\{/ \mathrm{ti} /, / \mathrm{dj} /\}</ \mathrm{di} /$

Should the predictions in (6a-b) be confirmed then this would lend phonetic support to the hierarchy in (7).

\section{$4 \quad$ A phonetic analysis}

In this section we present phonetic evidence supporting the predictions in (6) and the hierarchy in (7). We present below the results of three acoustic studies of / ti tj di dj/ sequences, one with German speakers only (section 4.1) and the second and third with German and Polish speakers, respectively (section 4.2). In our studies we measured the duration from the release of $/ \mathrm{t} d /$ to the onset of the following vocoid (the start of the fundamental frequency and continuous formants) as illustrated in Figure 1. This phase includes phonetic instances such as burst friction (BF) and aspiration (A) and will be referred to below as the 'friction phase'.

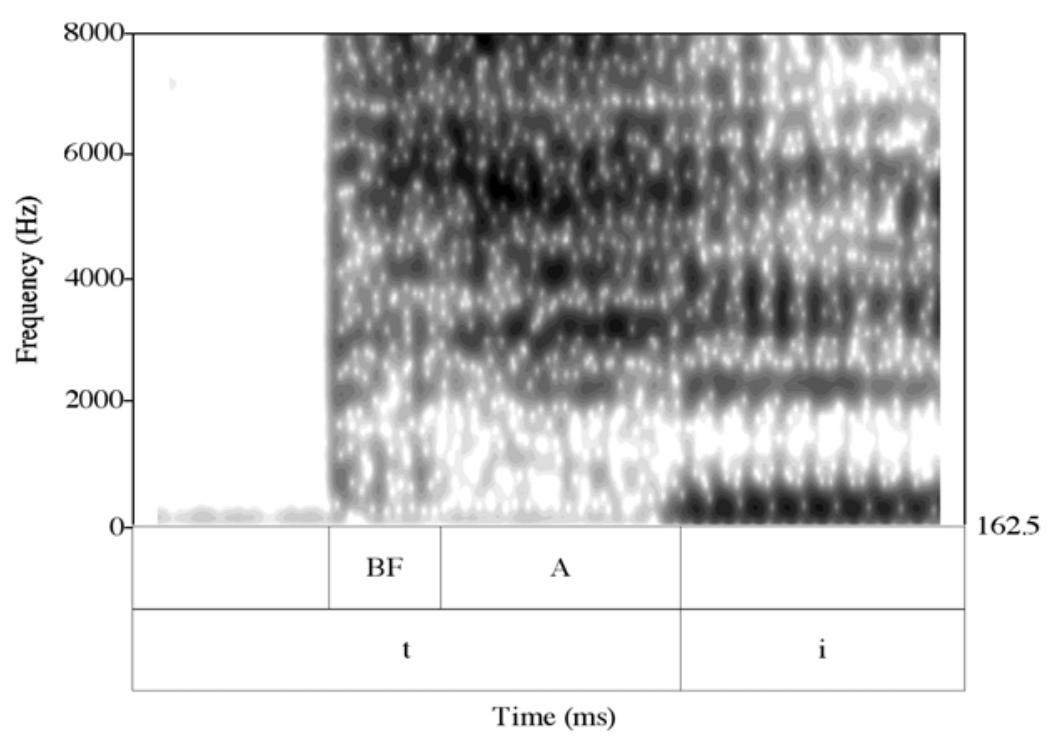

Figure 1: Spectrogram of a sample friction phase. $\mathrm{BF}=$ burst friction and $\mathrm{A}=$ aspiration.

As can be seen in Figure 1 burst friction differs considerably from aspiration. While burst friction immediately follows the closure phase of $/ t /$, aspiration occurs between the burst friction and the following vocoid. Burst friction is generated at the supraglottal constriction and shows a spectral prominence in the 
frequency range from 3500 to 7000 for an alveolar stop which is due to a front cavity that is 1-2 cm long, cf. e.g. Stevens et al. (1999).

Aspiration on the other hand is generated at the glottis and shows a stronger concentration of energy in the higher frequency region but also formant like peaks in lower frequency regions. Furthermore, it displays attenuation, or lack of the first formant, the so-called F1 cutback, cf. Liberman at al. (1958). If the stop is followed by a high vocoid, as in Figure 1, aspiration overlaps with friction generated at the constriction of this vocoid, cf. Hanson \& Stevens (2003). Aspiration is considerably longer durationally than burst friction. What also distinguishes burst friction from aspiration is the amplitude, since the amplitude of the former decreases as the cross-sectional area of its supraglottal constriction increases, cf. Stevens (1998: 362). When the noise generated at the constriction becomes dominated by the noise generated at the glottis, then the amplitude of aspiration increases.

In our experminent we expect the duration of the friction phase for $/ \mathrm{tj} /$ to be significantly longer than that of $/ \mathrm{ti} /(=$ prediction $6 \mathrm{a}$ ). Prediction (6b) similarly leads us to hypothesize that the friction phase of $/ \mathrm{dj} /$ should be significantly longer than that of /di/. Furthermore, we expect the duration of the friction phase of $/ \mathrm{di} \mathrm{dj} /$ to be shorter than that of the sequences with $/ \mathrm{ti} \mathrm{tj} /$ ( predictions $6 \mathrm{c}$ and $6 \mathrm{~d}$ ). Two experiments were conducted in order to test these predictions. In the first one the friction phase of $/ \mathrm{ti} / \mathrm{vs}$. $/ \mathrm{tj} /$ and $/ \mathrm{di} / \mathrm{vs} . / \mathrm{dj} / \mathrm{in}$ contrastive pairs of nonce words was measured, e.g. [ti'a] vs. [tja]. Since all four of the speakers in this experiment often glided the /i/ to [j] in items like [ti'a], we conducted a second experiment with near minimal pairs of nonce words such as [tjak] vs. [tik], in which the gliding of /i/ to [j] was not possible. It will be shown below that the results of Experiment 1 support (6c-d). The results of Experiment 2 support (6a-d).

\subsection{Experiment 1}

Four speakers of German (two male, CG and JD, and two female, SF and $\mathrm{SH}$ ) participated in an acoustic study in which the duration of friction phase of the stops $/ \mathrm{t} /$ and $/ \mathrm{d} /$ was measured. The four speakers were asked to read the twenty four nonce sequences given in Table 1 in a randomized order. All are phonotactically well-formed in German. ${ }^{2}$ Capitals indicate stress.

2 Sequences of [di] and [ti] plus following vowel are not that common in German, but occur in foreign words such as Diagramm [diagsam] 'diagram' and Tiara [tia:sa] 'tiara'. An optional gliding of the unstressed / $\mathbf{i}$ / in these positions is possible. Examples containing [dj] occur in many (frequent) nonnative words, e.g. Studium ['Stu:djom] 'studies' (sg.). Examples of [tj] sequences are rare but they are attested in Adjektiv ['atjekti:f] 'adjective'. 
Table 1: Twenty four sequences involving / $\mathrm{d} /$ with / $\mathrm{j} /$ used in Experiment 1.

$\begin{array}{lll}\text { tiA } & \text { atiA } & \text { atsiA } \\ \text { tjA } & \text { atjA } & \text { atsjA } \\ \text { tiU } & \text { Atia } & \text { Atsia } \\ \text { tjU } & \text { Atja } & \text { Atsja } \\ \text { diA } & \text { adiA } & \text { astiA } \\ \text { djA } & \text { adjA } & \text { astjA } \\ \text { diU } & \text { Adia } & \text { Astia } \\ \text { djU } & \text { Adja } & \text { Astja }\end{array}$

The nonce words were embedded in the frame sentence "Ich habe _ gesagt" "I said _.' The subjects repeated the test words with the frame sentence five times at normal speed.

Figure 2 shows broad band spectrograms (with a window length of $5 \mathrm{~ms}$ and a dynamic range of $50 \mathrm{~dB}$ ) for the examples /atiA/ and /atj $\mathrm{A} /$ for speaker CG. The duration of the friction phase is indicated in the examples in the first row below each spectrogram (the /a/ at the beginning and at the end of each word are not given in their whole duration).

(a) atiA

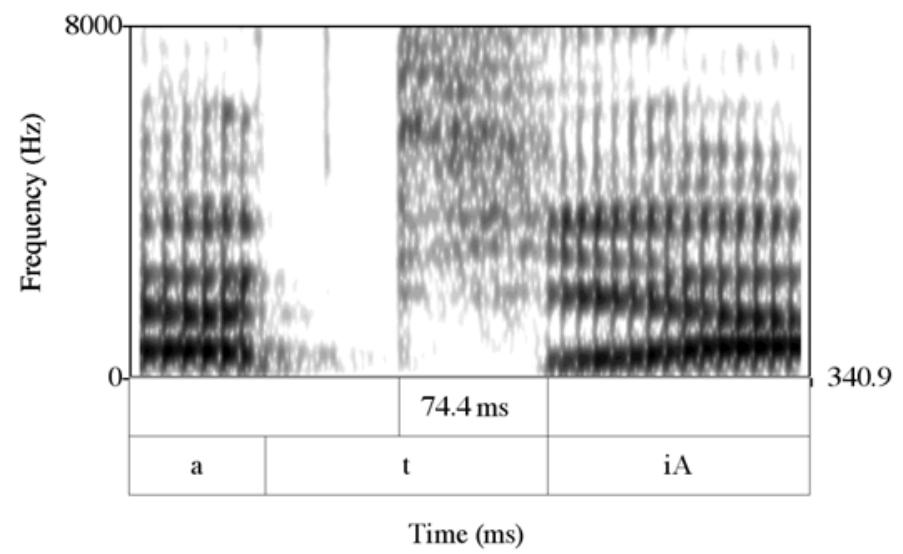

(b) $\operatorname{atj} \mathrm{A}$

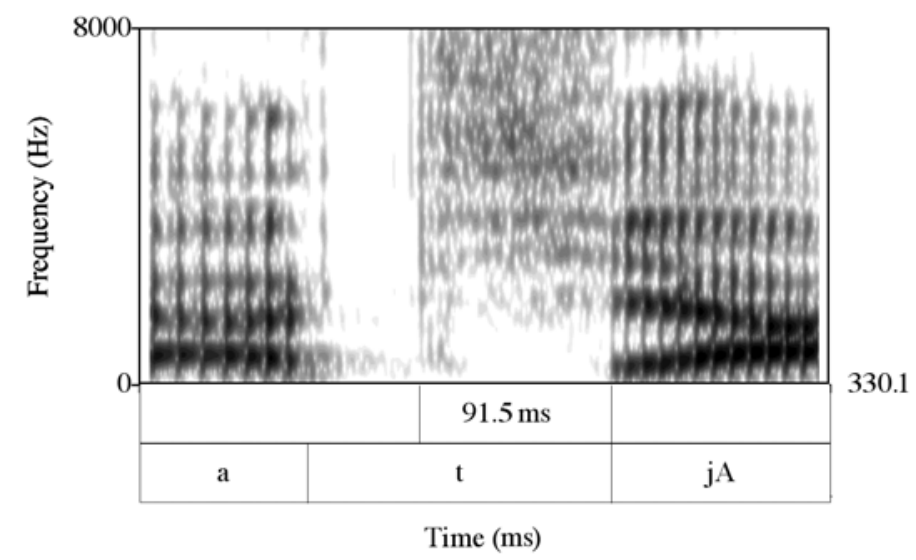

Figure 2: Spectrograms of (a) atiA and (b) atjA (German speaker CG).

See Hall (2004) for discussion of the distribution of [tj] and [tsj] sequences in Modern German. 
A comparison of the two spectrograms in Figure 2 shows that the example with a following /i/ in (a) has a shorter friction phase than the one with a glide $/ j /$ in (b).

Examples for a voiced stop followed by $/ \mathrm{i} /$ and $/ \mathrm{j} /$ are given in Figure 3, again from speaker CG.

(a) adiA

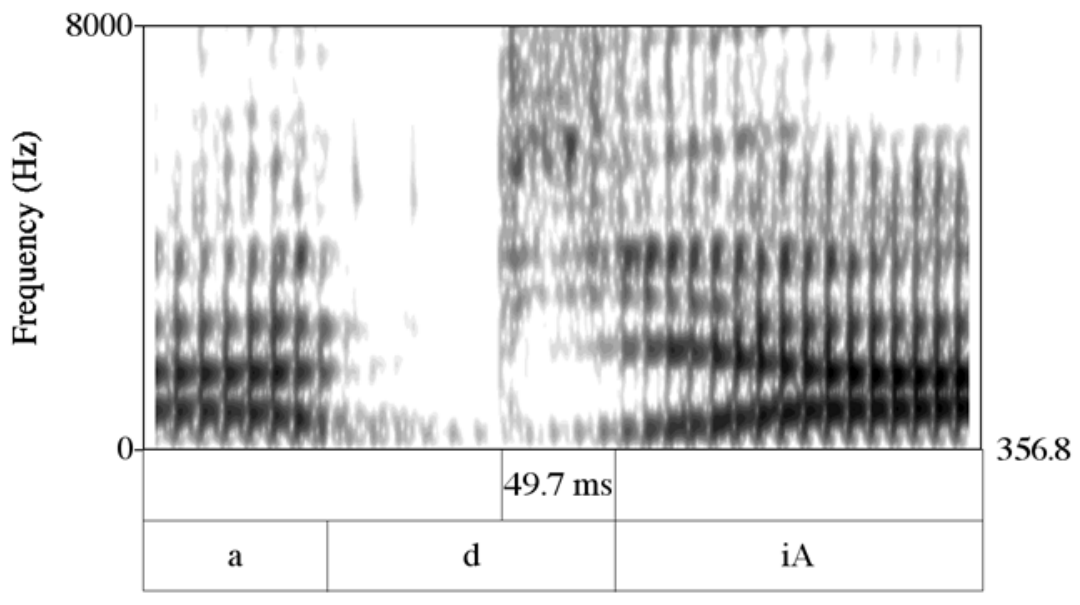

Time (ms)

(b) $\operatorname{adj} \mathrm{A}$

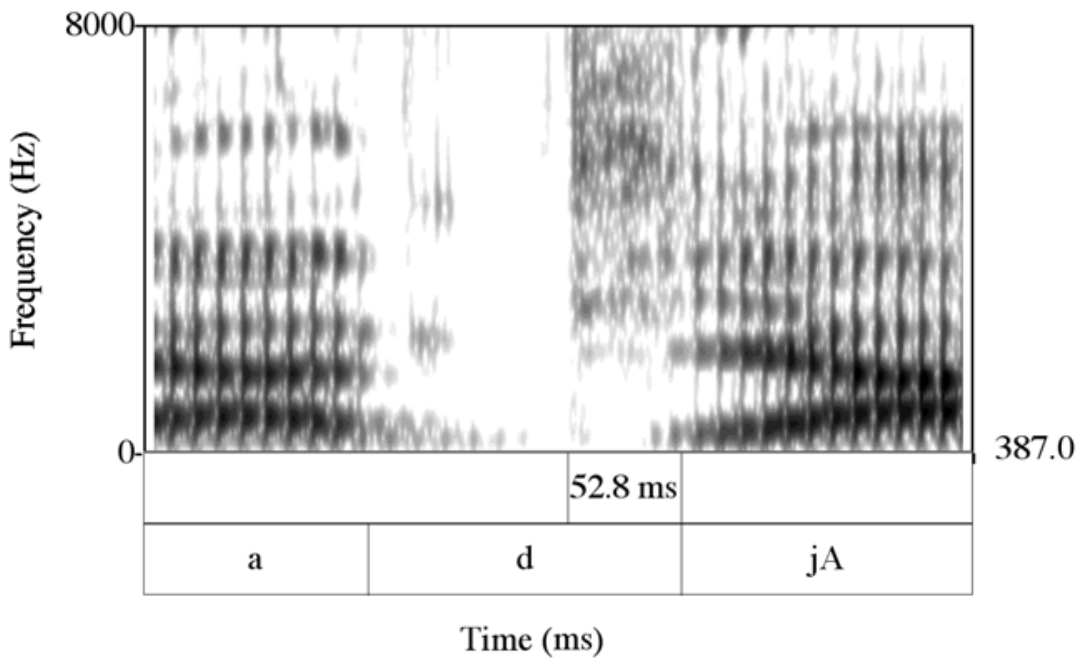

Figure 3: Spectrograms of (a) atiA and (b) atjA (German speaker CG).

For some speakers, there was no visible friction phase in the spectrograms of the voiced stop, e.g. the [d] in Adja for speaker SH in Figure 4. In cases like these we took $0 \mathrm{~ms}$ as the value for friction duration. 


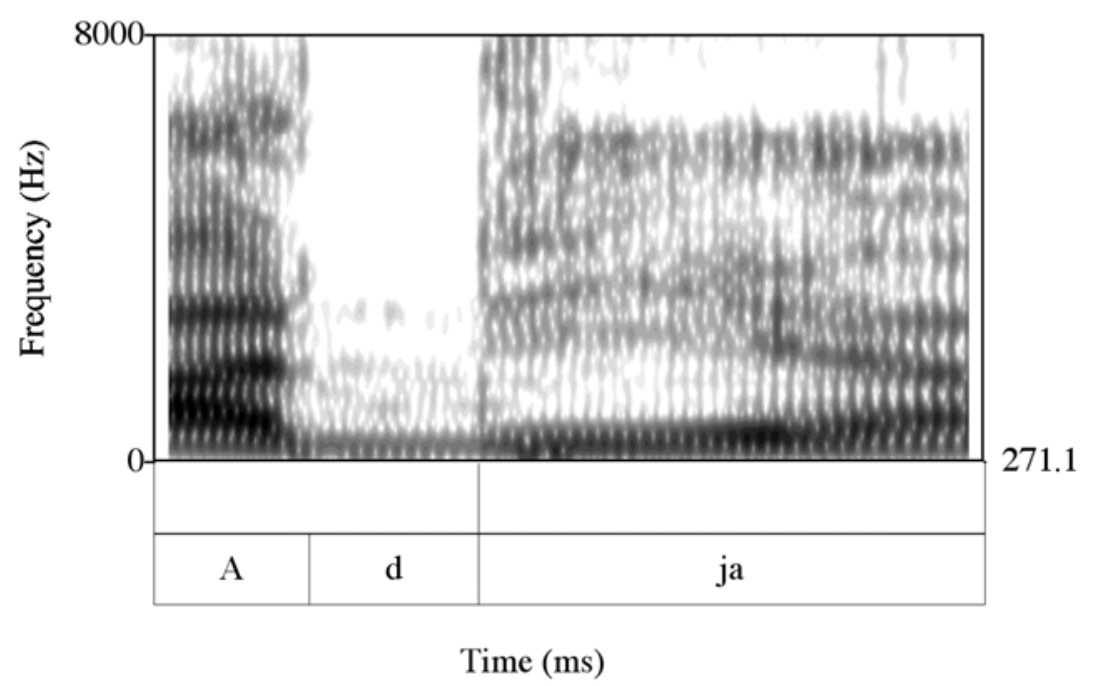

Figure 4: Spectrogram of adjA (German speaker SH).

For all four speakers together, the friction duration after $/ \mathrm{d} /$ is shorter than it is after $/ t /$, as illustrated in the following Graph 1. The vertical axis indicates duration of the friction phase in [s]. The different shadings of the bars correspond to $/ \mathrm{i} /$ or $/ \mathrm{j} /$, as indicated in the legend to the right.

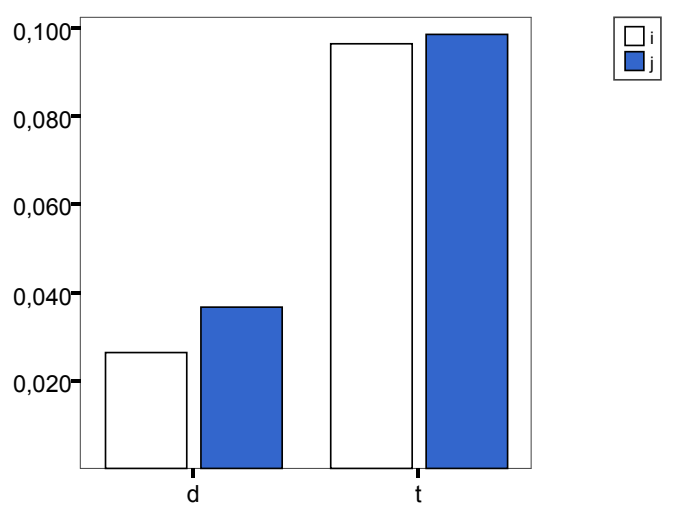

Graph 1: The average duration of friction in $s$ after $/ d /$ or $/ t /$ over five tokens of the test words for all speakers.

The results summarized in Graph 1 are important because they support predictions (6b-d). A two-factorial ANOVA ${ }^{3}$ with $/ \mathrm{t}, \mathrm{d} /$ and $/ \mathrm{i}, \mathrm{j} /$ as independent variables and friction duration as dependent variable shows that the difference between the friction phase duration for $/ \mathrm{tj} / \mathrm{vs}$. $/ \mathrm{dj} /(=6 \mathrm{c})$ and for $/ \mathrm{ti} / \mathrm{vs} . / \mathrm{di} /(=6 \mathrm{~d})$ is highly significant $(\mathrm{F}(1,239)=263.432, \mathrm{p}<.001, \mathrm{~F}(1,238)=284.909$ $\mathrm{p}<.001)$. A comparison of the friction phase duration for $/ \mathrm{di} / \mathrm{vs} . / \mathrm{dj} /(=6 \mathrm{~b})$ on the left of Graph 1 illustrates that the difference is also significant $(F(1,159)=$ $8.944 \mathrm{p}<.01)$. We illustrate below that $(6 \mathrm{c}-\mathrm{d})$ and to a lesser extent $(6 \mathrm{~b})$ are also

\footnotetext{
${ }^{3}$ All statistical calculations were made in SPSS 11.5.1.
} 
borne out for each of the four speakers individually. By contrast, prediction (6a) in Graph 1 is not nearly as robust $(\mathrm{F}(1,318)=.417 \mathrm{p}=.519)$. Similar results were obtained for the individual speakers as well (see below).

Graph 2 shows the results of Experiment 1 split between speakers. Note that the order of the single box plots within each window corresponds to the order of bars in Graph 1. Each boxplot shows the median, quartiles, and extreme values within a category. The median value is shown by a horizontal line displayed in each of the boxplots. The vertical line shows $95 \%$ of the data and is limited by the highest and the lowest values. The box length is the interquartile range and it covers $50 \%$ of the data. It is limited by the first $(25 \%)$ and third quartile (75\%). Graph 2 presents also outliers marked by small circles above the boxes which represent cases with values between 1.5 and 3 box lengths from the upper or lower edge of the box.
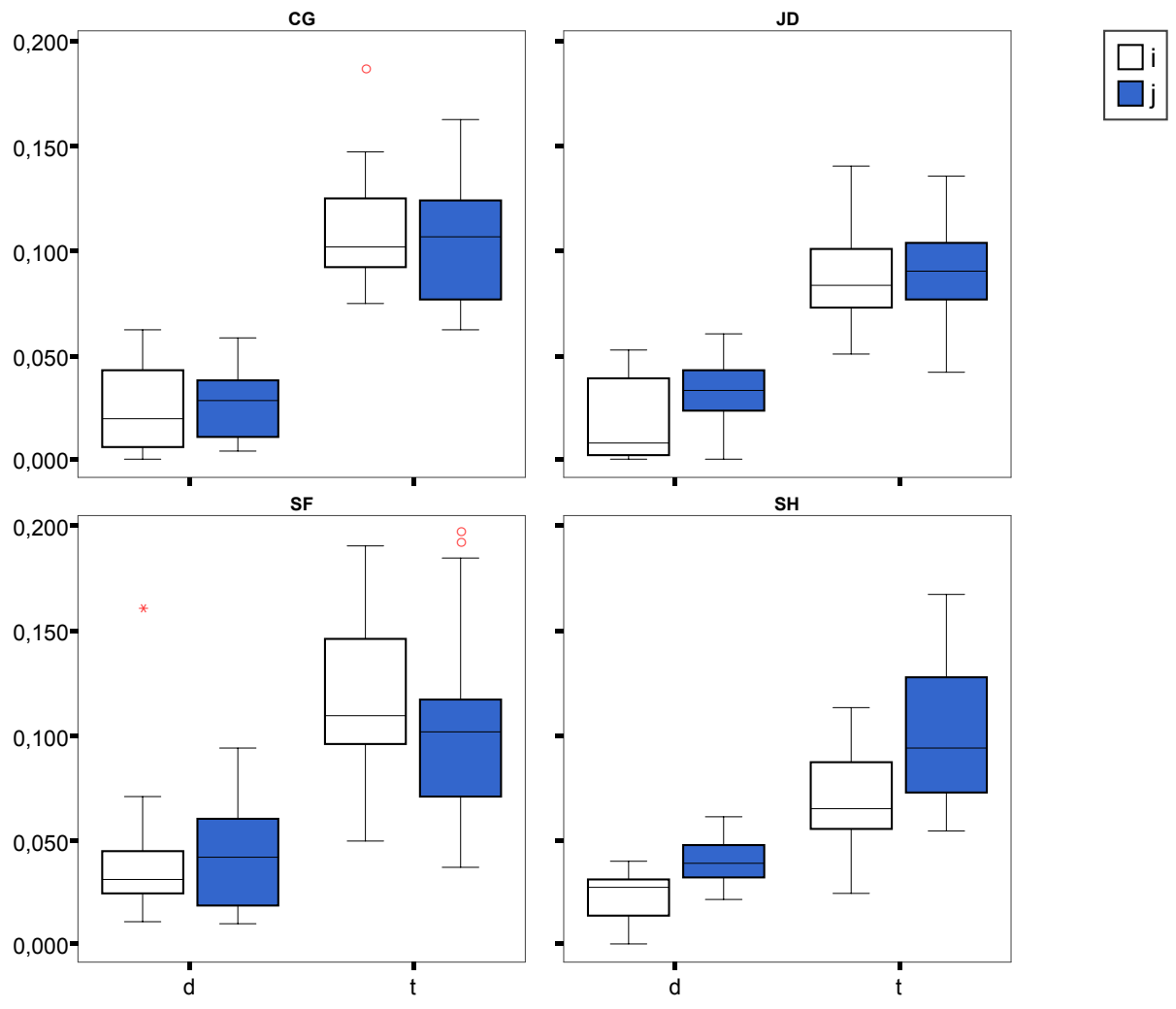

Graph 2: The average duration of friction in $\mathrm{s}$ after /d/ or / $/$ / over five tokens of the test words split according to speakers. Boxplots correspond to means of friction duration.

An examination of Graph 2 illustrates that prediction (6c-d) are borne out but that $(6 a-b)$ are not. For all four speakers $(6 c-d)$ are confirmed because the difference in friction phase duration for $/ \mathrm{t} j /$ is significantly longer than for $/ \mathrm{dj} /$. Similarly, the friction phase in /ti/ is significantly longer than in /di/; speaker CG $\mathrm{F}(1,59)=188.788, \mathrm{p}<.001$, speaker JD $\mathrm{F}(1,59)=140.243, \mathrm{p}<.001$, speaker SF $\mathrm{F}(1,59)=62.166, \mathrm{p}<.001$, speaker SH $\mathrm{F}(1,58)=69.382, \mathrm{p}<.001$. 
By contrast, predictions (6a) (and to a lesser extent 6b) are not consistently confirmed by the four individual speakers. Only speaker SH has a significant difference between $/ \mathrm{tj} /$ and $/ \mathrm{ti} /(\mathrm{F}(1,78)=22.971 \mathrm{p}<.001)$. Speaker JD has a slightly longer friction phase duration for $/ \mathrm{t} \mathrm{j} /$ than for $/ \mathrm{ti} /$, but this difference is not significant $(F(1,79)=.072, p=.789)$. Speakers $C G$ and SF show a reverse duration of friction phase than predicted by (6a): for both the friction duration for $/ \mathrm{ti} /$ is longer than for $/ \mathrm{tj} /$. (6b) derives support from speakers $\mathrm{SH}$ and JD, whose friction phase duration for $/ \mathrm{dj} /$ is significantly longer than $/ \mathrm{di} /$ (speaker SH: $F(1,39)=21.018, p<.001$, speaker JD: $F(1,39)=7.019, p<.05)$. For speakers $\mathrm{CG}$ and $\mathrm{SF} / \mathrm{dj} /$ is longer (although not significantly) than $/ \mathrm{di} /$ which is the reverse from our prediction in (6b).

The unexpected results concerning predictions (6a-b) can be accounted for by the fact that most nonce words with /i/ plus vowel sequences surfaced as [j] and thus the minimal pairs illustrating $/ \mathrm{i} / \mathrm{-} / \mathrm{j} /$ contrasts were neutralized. The gliding of $/ \mathrm{i} /$ to $[\mathrm{j}]$ could be observed in a clear majority of the tokens containing [i] plus vowel for all speakers but SH. This point can be attributed to the fact that [i] and [j] are usually analyzed as allophones of /i/ in German which are distributed in such a way that the glide [j] only occurs before a vowel (see, e.g. Wiese 1996). In order to avoid the occurence of gliding, we conducted a second experiment in which gliding is not possible.

One finding in Experiment 1 we did not predict is that the friction phase duration of $/ \mathrm{ti} /$ is significantly longer than that of $/ \mathrm{dj} /(\mathrm{p}<.001$ for all speakers). In section 5 we return to this point.

\subsection{Experiment 2 and 3}

In the second experiment, four native speakers of German (the same subjects as in the first experiment) were asked to read 28 nonce words embedded in a carrier sentence "Ich habe _ gesagt" 'I said _'. The nonce words in Table 2 were presented in a randomized order and the subjects repeated the sequences ten times at normal speed. Stressed syllables are indicated by capital letters.

Table 2: Twenty four sequences involving /t d/ with / $\mathrm{j} /$ used in Experiment 1 .

$\begin{array}{llll}\text { Atik } & \text { aTIK } & \text { Adik } & \text { aDIK } \\ \text { Itik } & \text { iTIK } & \text { Idik } & \text { iDIK } \\ \text { Utik } & \text { uTIK } & \text { Udik } & \text { uDIK } \\ \text { Atjak } & \text { aTJAK } & \text { Adjak } & \text { aDJAK } \\ \text { Itjak } & \text { iTJAK } & \text { Idjak } & \text { iDJAK } \\ \text { Utjak } & \text { uTJAK } & \text { Udjak } & \text { uDJAK } \\ \text { Atjik } & \text { aTJIK } & \text { Adjik } & \text { aDJIK } \\ \text { Atjuk } & \text { aTJUK } & \text { Adjuk } & \text { aDJUK }\end{array}$


In contrast to Table 1, there are no minimal pairs in Table 2 involving [i] and [j], e.g. Atia vs. Atja. Instead, we see in Table 2 that there are pairs like Atik (in which a consonant and not a vowel follows [i]) vs. Atjak. In this way we avoid the possibility of converting / $\mathrm{i} /$ into [j] before a vowel because there is no vowel following the $/ \mathrm{i} /$ in items like Atik. Our results are summarized in the following graphs.

Graph 3 presents the average duration of friction after $/ \mathrm{d} / \mathrm{and} / \mathrm{t} / \mathrm{when}$ followed by /i/ or /j/ for all German speakers together.
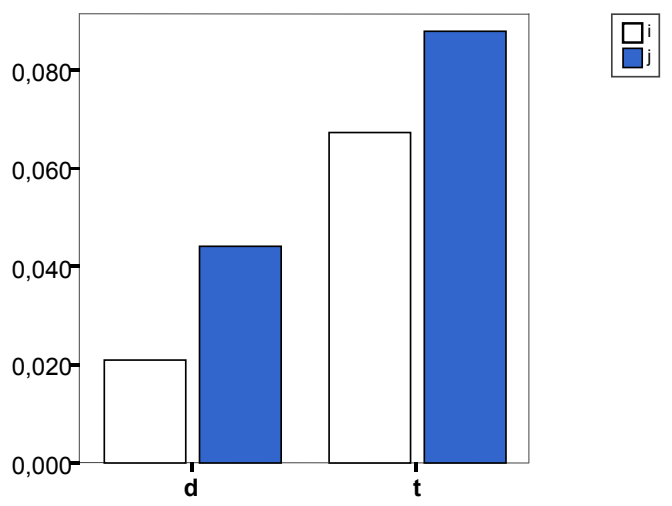

Graph 3: The average duration of friction in $\mathrm{s}$ after /d/ or /t/ for all German speakers.

The results of Experiment 2, as summarized in Graph 3, support predictions (6a-d). (6a) is supported because the friction duration for $/ \mathrm{t} \mathrm{j} /$ is significantly longer than $/ \mathrm{ti} /(\mathrm{F}(1,634)=189.122 \mathrm{p}<.001)$, as is $(6 \mathrm{~b})$ because the friction duration for $/ \mathrm{dj} /$ is significantly longer than $/ \mathrm{di} /(\mathrm{F}(1,643)=265.508 \mathrm{p}<.001)$. (6c-d) also derive support because the friction phase for $/ \mathrm{tj} /$ is significantly longer than for $/ \mathrm{dj} /,(\mathrm{F}(1,795)=1112.039, \mathrm{p}<.001)$. For $/ \mathrm{ti} / \mathrm{vs}$. $/ \mathrm{di} /$ the results are also significant: $(\mathrm{F}(1,482)=887.476, \mathrm{p}<.001)$.

As in Experiment 1, the friction phase for $/ \mathrm{t} \mathrm{i} /$ in Experiment 2 is significantly longer than $/ \mathrm{dj} /(\mathrm{F}(3,1278)=809.933, \mathrm{p}<.001)$, the latter results follow from a post-hoc Scheffé test). See section 5 for discussion.

Graph 4 presents results in the form of box plots, as obtained for individual speakers. The order of the single box plots within each window corresponds to the order of bars in Graph 3. Note that apart from outliers there are also extreme cases marked by asterisks which represent cases with values more than 3 box lengths from the upper or lower edge of the box. Other parameters are the same as in Graph 2. 

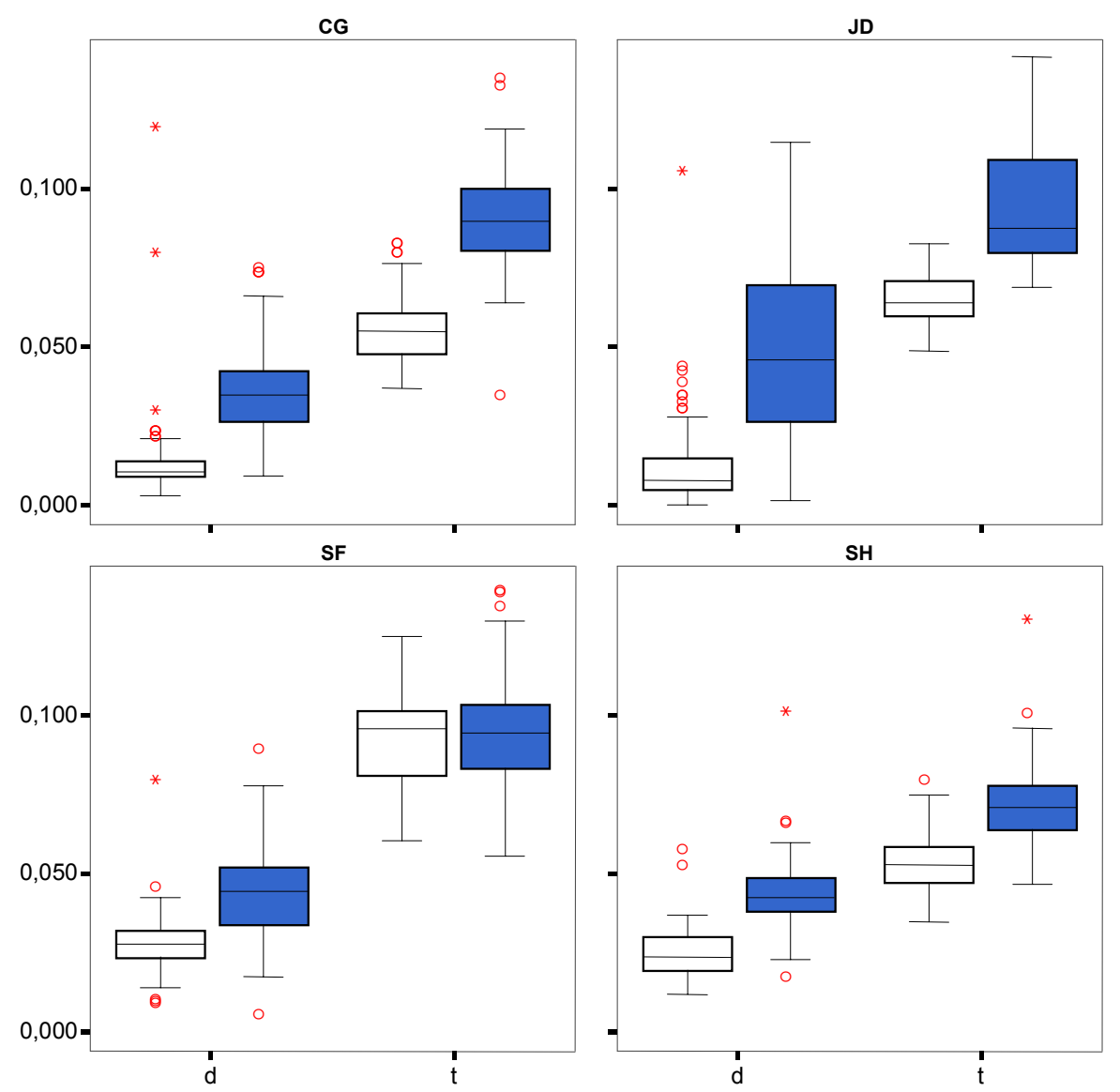

Graph 4: The average duration of friction in $\mathrm{s}$ after /d/ or / $\mathrm{t} / \mathrm{split}$ according to speakers.

German speakers averaged over vowels and stress condition.

Graph 4 illustrates that all four speakers of German individually support predictions (6c-d): Statistically, the friction phase is significantly longer in $/ \mathrm{tj} /$ than in $/ \mathrm{dj} /$ (for speaker CG $\mathrm{F}(1,198)=687.597 \mathrm{p}<.001$, speaker JD $\mathrm{F}(1,198)=164.580 \mathrm{p}<.001$, speaker $\mathrm{SF} F(1,198)=506.637 \mathrm{p}<.001$, and speaker SH $F(1,198)=299.221 \mathrm{p}<.001)$ and the friction is significantly longer in $/ \mathrm{ti} /$ than in $/ \mathrm{di} /$ for speaker CG $\mathrm{F}(1,120)=244.719 \mathrm{p}<.001$, speaker JD $\mathrm{F}(1,198)=164.580$ $\mathrm{p}<.001, \quad$ speaker SF $\mathrm{F}(1,119)=838.043, \quad \mathrm{p}<.001, \quad$ and speaker $\mathrm{SH}$ $\mathrm{F}(1,120)=278.373 \mathrm{p}<.001$. Prediction $(6 \mathrm{~b})$, that the friction phase in $/ \mathrm{dj} /$ is of longer duration than in $/ \mathrm{di} /$, is also significantly supported by all four speakers (for each speaker $\mathrm{p}<.001$ ). Prediction (6a), that the friction phase in $/ \mathrm{t} j /$ is of longer duration than in /ti/, is supported by speakers CG, JD and SH but not by speaker SF who has almost equal values for $/ \mathrm{t} j /$ and $/ \mathrm{ti} /$, the difference is not significant: $F(1,157)=156, p=.693$.

In light of these results the question arises whether the predictions in (6) and the proposed hierarchy in (7) are language specific or whether they can be confirmed by data from other languages. For reasons of comparison we included an investigation of Polish. To be sure, any one of a number of languages could be taken for comparison, but we opted for Polish because this language differs from German in terms of voicing: While German contrasts voiceless with 
voiceless aspirated stops, i.e. $/ \mathrm{p} \mathrm{t} \mathrm{k/} \mathrm{vs} / \mathrm{p}^{\mathrm{h}} \mathrm{t}^{\mathrm{h}} \mathrm{k}^{\mathrm{h}} /$ (see, e.g. Jessen \& Ringen 2002), Polish contrasts voiced and voiceless stops, i.e. /b d g/ with $/ \mathrm{p} \mathrm{t} \mathrm{k/.}$

This language-specific difference in the realization of the voicing contrast leads us to expect a difference in overall friction length: Since the duration from the burst until the onset of a vowel is shorter for truly voiced stops than for voiceless ones and aspiration adds to this length of friction (see the beginning of section 4), we expect Polish to show generally shorter friction duration than German.

Four native speakers of Polish (two female DZ, MR and two male SL, KZ) were asked to read the nonce words presented in Table 2 in the carrier sentence 'Powiedzialem ... do ciebe' 'I said... to you' at normal speed. ${ }^{4}$

The average duration of the friction phase duration as obtained by all four speakers together for $/ \mathrm{di} /, / \mathrm{dj} /, / \mathrm{ti} /$ and $/ \mathrm{tj} /$ is presented in Graph 5. The friction is in $\mathrm{s}$.

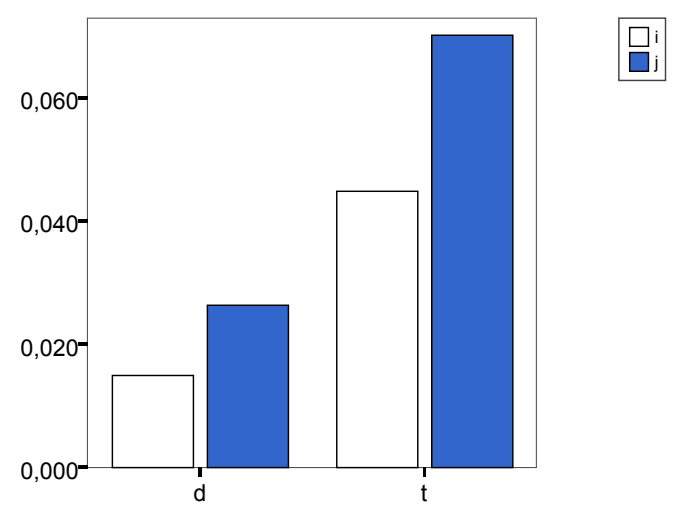

Graph 5: The average duration of friction in $\mathrm{s}$ after /d/ or /t/ for all Polish speakers.

The results presented in Graph 5 support the predictions in (6a-d). Again, a twofactorial ANOVA with $/ \mathrm{d}, \mathrm{t} /$ and $/ \mathrm{i}, \mathrm{j} /$ as independent variables and friction duration as dependent variables reveals that all differences presented in Graph 5 are highly significant: $/ \mathrm{tj} / \mathrm{vs} . / \mathrm{ti} /(\mathrm{F}(1,624)=248.425 \mathrm{p}<.001), / \mathrm{dj} / \mathrm{vs} . / \mathrm{di} /$ $(\mathrm{F}(1,643)=49.616 \mathrm{p}<.001), / \mathrm{tj} / \mathrm{vs} . / \mathrm{dj} /(\mathrm{F}(1,789)=740.485 \mathrm{p}<.001)$, and $/ \mathrm{ti} / \mathrm{vs}$. $/ \mathrm{di} /(\mathrm{F}(1,478)=559.761 \mathrm{p}<.001)$.

As for German, the friction duration for /ti/ in Polish is significantly longer than for $/ \mathrm{dj} /(\mathrm{p}<.001)$. See section 5 below for discussion.

Graph 6 presents the results split between the individual speakers in the form of box plots.

4 The sequences [ $\mathrm{tj} \mathrm{dj}]$ plus vowel are well-formed in Polish. They occur in words of foreign origin, e.g. [dj]alekt 'dialect', [tj]ara 'tiara.' 

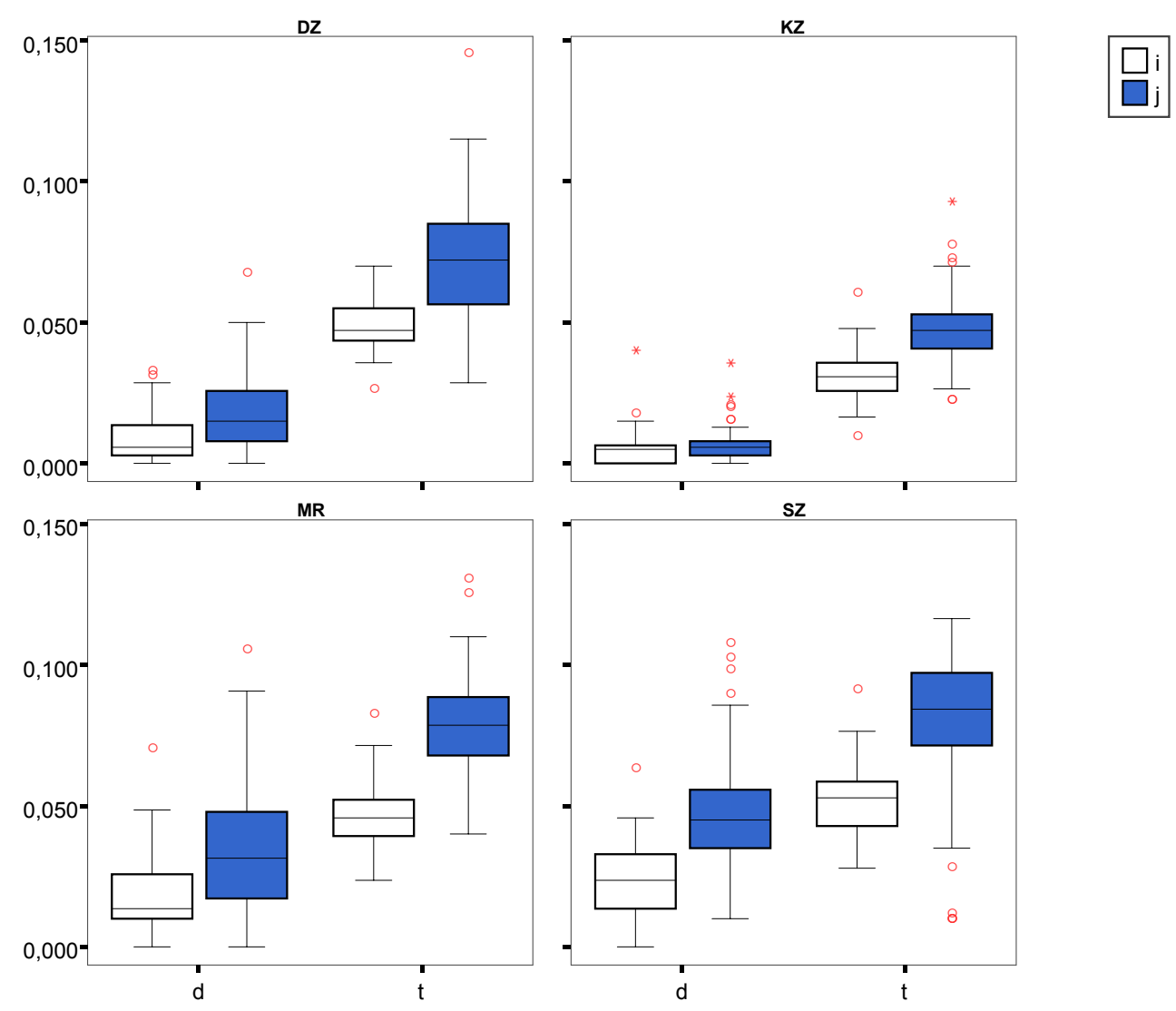

Graph 6: The average duration of friction in $s$ after /d/ or / $/$ / split according to speakers. Polish speakers.

The results in Graph 6 show that predictions $(6 a, c-d)$ are supported by the results from all four speakers (for all three predictions: for (6a) speaker DZ $\mathrm{F}(1,157)=68.830 \mathrm{p}<.001$, speaker $\mathrm{KZ} F(1,158)=95.819, \mathrm{p}<.001$, speaker MR $\mathrm{F}(1,148)=179.022 \mathrm{p}<.001$, speaker SZ $\mathrm{F}(1,158)=90.152 \mathrm{p}<.001$, for $(6 \mathrm{c})$ speaker DZ $\mathrm{F}(1,199)=542.550 \mathrm{p}<.001$, speaker $\mathrm{KZ} \mathrm{F}(1,199)=1119.964$, $\mathrm{p}<.001$, speaker MR $\mathrm{F}(1,189)=252.337 \mathrm{p}<.001$, speaker SZ F $(1,199)=137.535$ $\mathrm{p}<.001$ and for $(6 \mathrm{~d})$ speaker DZ $\mathrm{F}(1,118)=599.272 \mathrm{p}<.001$, speaker KZ F(1, $119)=389.158, \mathrm{p}<.001$, speaker MR $\mathrm{F}(1,119)=176,979 \mathrm{p}<.001$, speaker SZ $\mathrm{F}(1,119)=134.688 \mathrm{p}<.001) .(6 \mathrm{~b})$ is supported by three speakers (speaker MR $\mathrm{F}(1,160)=25.943 \mathrm{p}<.001$, speaker SZ $\mathrm{F}(1,160)=66.688 \mathrm{p}<.01)$. By contrast, speaker $\mathrm{KZ}$ did not have a significant difference between the friction phase duration of $/ \mathrm{di} / \mathrm{vs}$. $/ \mathrm{dj} / . \mathrm{F}(1,160)=1.644 \mathrm{p}=.202$

Graph 7 shows a comparison of the results for German and Polish. The numbers on the top of the bars indicate mean friction duration in $\mathrm{s}$ as obtained in the given sequences. 


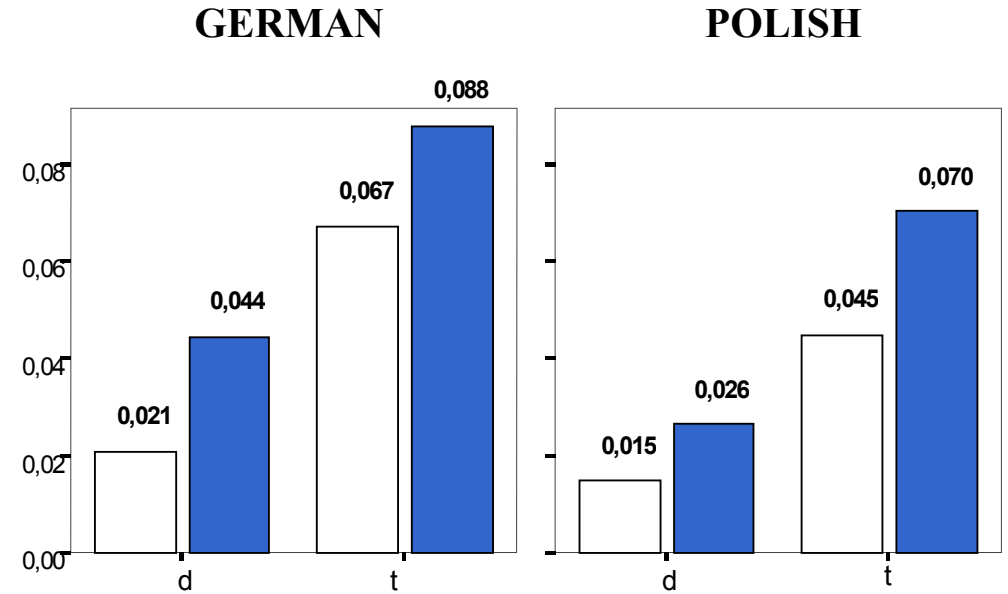

Graph 7: Comparison of the average duration of friction in $\mathrm{s}$ after $/ \mathrm{d} / \mathrm{or} / \mathrm{t} /$ for German and Polish speakers.

The results of Graph 7 show that the friction phase is on average longer in German than in Polish, which is in accordance with our expectations.

In addition to the voicing parameter (i.e. $/ \mathrm{t} / \mathrm{vs}$. $/ \mathrm{d} /$ ) and the parameter for the trigger (i.e. $/ \mathrm{i} / \mathrm{vs} . / \mathrm{j} /$ ) there are three other factors which could potentially influence the friction phase duration. We list them in (8):

(8) a. The quality of the vowel following $/ \mathrm{tj} /$ and $/ \mathrm{dj} /$

b. The quality of the vowel preceding $/ \mathrm{tj} /, / \mathrm{ti} /, / \mathrm{dj} /$ and $/ \mathrm{di} /$

c. The stress of the vowels adjacent to $/ \mathrm{tj} /, / \mathrm{ti} /, / \mathrm{dj} /$ and $/ \mathrm{di} /$

In the remainder of this section we report on the results of Experiment 2 with respect to the three parameters in (8).

As far as parameter (8a) is concerned, we did not include a vowel following /ti/ and /di/ sequences, as e.g. /atia/ or /atiu/, in order to exclude a possibility of realizing them with a glide, i.e. [atja], [atju]. Graphs 8a and b shows average friction durations dependent on the vowel following $/ \mathrm{tj} /$ and $/ \mathrm{dj} /$.

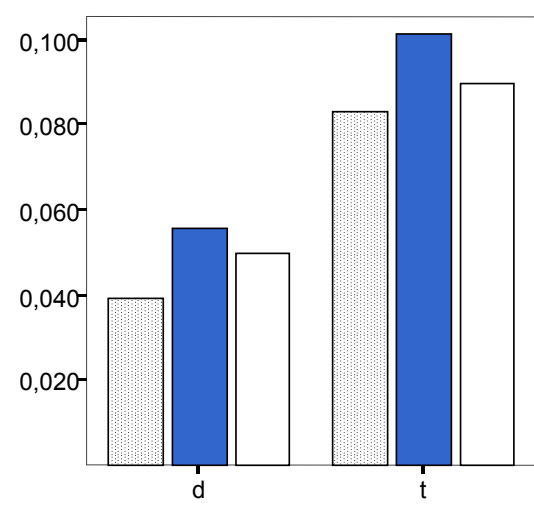

$a$
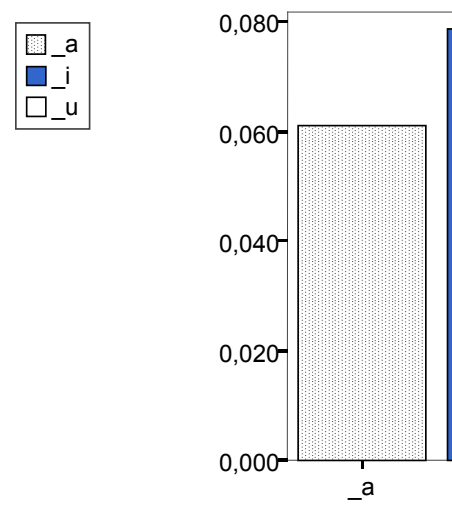

Graph 8: The average duration of friction in s dependent on the following vowel for $/ \mathrm{dj} /$ and $/ \mathrm{tj} /$ separately (a) and for $/ \mathrm{t} \mathrm{j} /$ and $/ \mathrm{dj} /$ together (b). German speakers. 
The results provide evidence that the friction duration in German $/ \mathrm{tj} /$ and $/ \mathrm{dj} /$ sequences is influenced by the following vowel. In particular, the longest friction occurs if the sequences are followed by $i$ and the shortest when they are followed by _a. Apart from the difference in mean friction duration between _u and_i in the /dj/ context (cf. [adjuk] vs. [adjik]), all other results are significant in comparison to each other. Taken together, an average friction for $/ \mathrm{tj} /$ and $/ \mathrm{dj} /$ leads to statistically significant differences: a following _i results in the longest duration followed by a following _u and finally by_a, cf. Graph 8b. According to a post-hoc Scheffé test all differences are statistically significant ( $\mathrm{i}$ vs. _a $\mathrm{F}(2,795)=23.664 \mathrm{p}<.001$,_i vs._u $\mathrm{p}<.05$, _u vs._a $\mathrm{p}<.01)$.

The influence of the vowel after $/ \mathrm{tj} /$ and $/ \mathrm{dj} /$ in the Polish items is given in Graphs 9a and b.

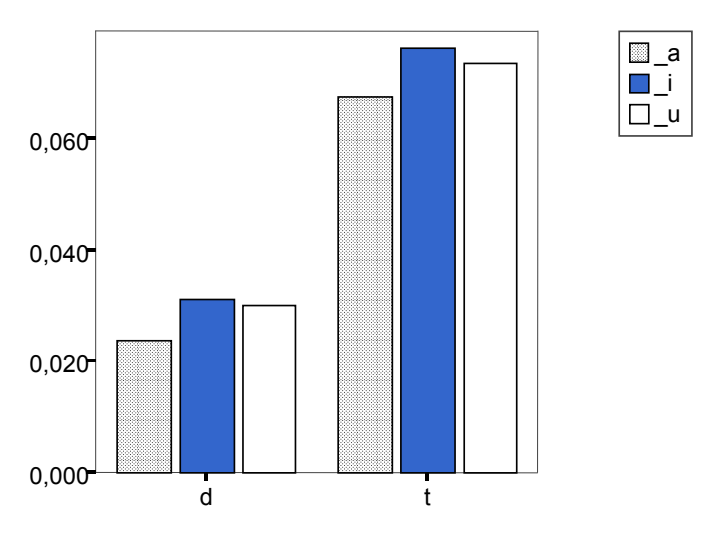

$a$

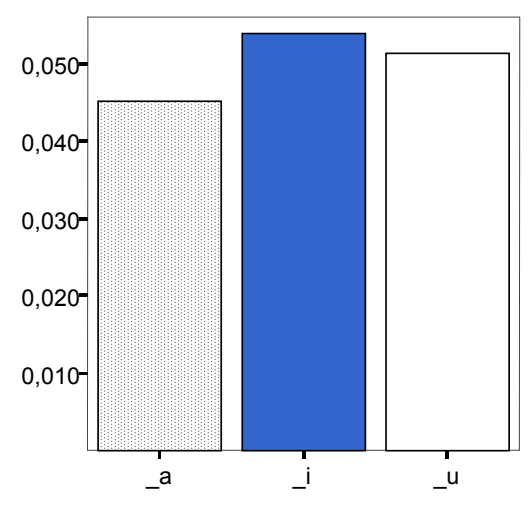

$\boldsymbol{b}$

Graph 9: The average duration of friction in s dependent on the following vowel for $/ \mathrm{dj} /$ and $/ \mathrm{tj} /$ separately (a) and for $/ \mathrm{tj} /$ and $/ \mathrm{dj} /$ together (b). Polish speakers.

As in German, the _i context in Polish triggers the longest duration in $/ \mathrm{t} \mathrm{j} /$ and $/ \mathrm{dj} /$ sequences. The second longest friction occurs in the _u context followed by the _a context. However, from a statistical point of view the influence of the following vowel is significant in only two contexts: for $/ \mathrm{tj} /$ the difference _a vs. $\mathrm{i}$ is significant $(\mathrm{F}(2,385)=5.630 \mathrm{p}<.01)$ and for $/ \mathrm{dj} /$ the same difference is only weakly significant $(\mathrm{F}(2,399)=4.659, \mathrm{p}<.05)$. Taking the results for $/ \mathrm{dj} / \mathrm{and} / \mathrm{tj} /$ together, Graph $9 \mathrm{~b}$ shows that the sequences in the $\mathrm{i}$ context have the longest friction duration which is only slightly longer than in the _u context and statistically not significant. The only statistically significant difference is attested between_a vs._i contexts $(\mathrm{F}(2,785)=5.509, \mathrm{p}<.05)$. The influence of vowel quality on a preceding glide and its consequence on friction duration is discussed in section 6.4 below.

Another factor we varied in this experiment was the preceding vowel, cf. (8b). Here all items of Table 2 were included in the calculations. Graphs 10a and 
$10 \mathrm{~b}$ show how the vowels $\mathrm{a}_{-}, \mathrm{i}_{-}$and $\mathrm{u}_{-}$influence the friction length of the stopvocoid sequences in German.
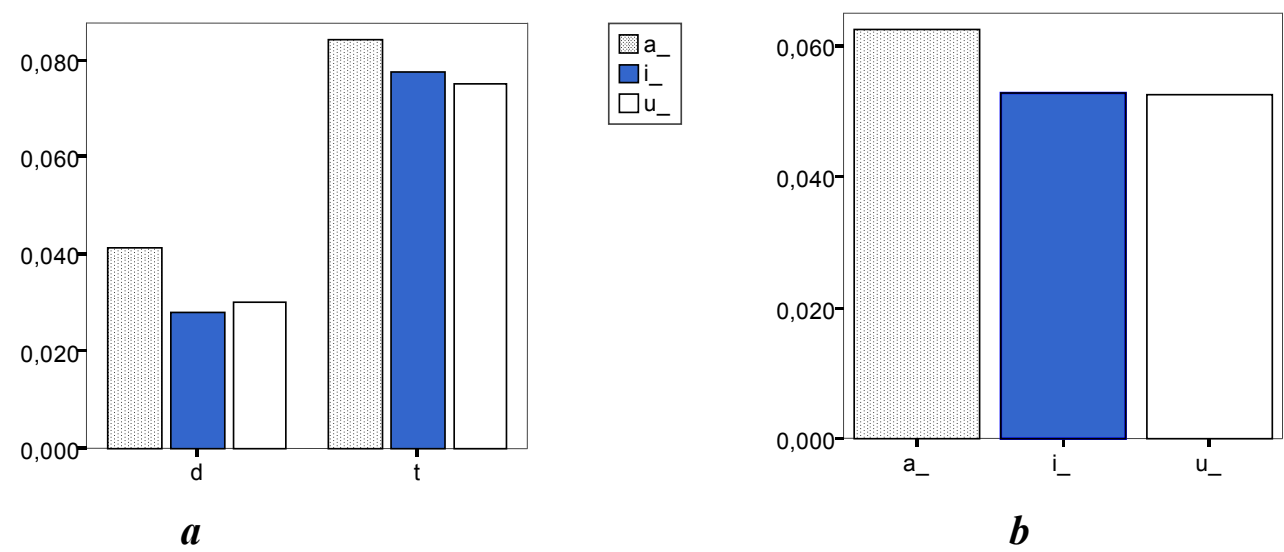

Graph 10: The average duration of friction in s dependent on the preceding vowel for $/ \mathrm{dj} /$ and $/ \mathrm{tj} /$ separately (a) and for $/ \mathrm{tj} /$ and $/ \mathrm{dj} /$ together (b). German speakers.

Results obtained for German show that if $/ \mathrm{dj} /$ or $/ \mathrm{tj} /$ are preceded by a_ the friction is longest. Other contexts do not show any clear tendencies, cf. Graph 10a. Statistically, the differences in the $a_{-}$vs. $u_{-}$context is highly significant for $/ \mathrm{t} /$ and $/ \mathrm{d} /$ (for $/ \mathrm{t} / \mathrm{F}(2,634)=12.244, \mathrm{p}<.001$, for $/ \mathrm{d} / \mathrm{F}(2,634)=30,297$ $\mathrm{p}<.001)$. The difference between the $\mathrm{a}_{-}$vs. $\mathrm{i}_{\text {_ context }}$ is significant in $/ \mathrm{t} /$ sequences $(\mathrm{p}<.01)$ and highly significant in $/ \mathrm{d} /$ sequences $(\mathrm{p}<.001)$. The $i_{-}$vs. $u_{-}$ context is significant neither in $/ t /$ nor in $/ d /$ sequences. This context does not influence the friction length if all items are calculated together, cf. Graph $10 \mathrm{~b}$. Here, the contexts $a_{-}$vs. $u_{-}$and $a_{-}$vs. $i_{-}$are highly significant (for both $\mathrm{F}(2,1278)=16.460 \mathrm{p}<.001)$.

Graphs 11a and 11b present the results of the influence of the preceding vowel obtained for Polish speakers.

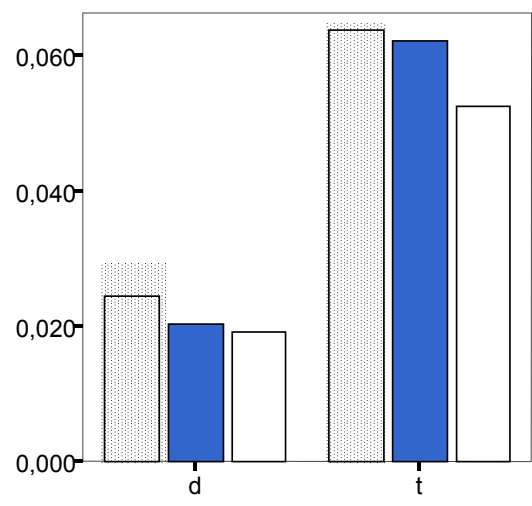

$a$
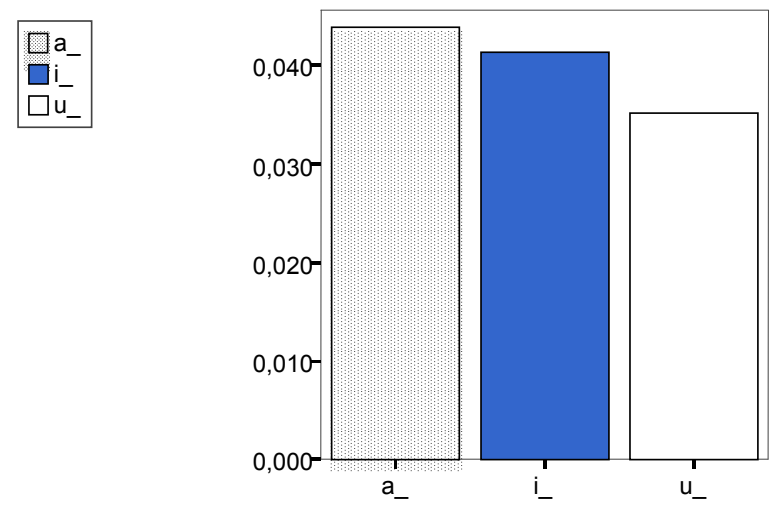

$b$

Graph 11: The average duration of friction in s dependent on the preceding vowel for $/ \mathrm{dj} /$ and $/ \mathrm{tj} /$ separately (a) and for $/ \mathrm{tj} /$ and $/ \mathrm{dj} /$ together (b). Polish speakers. 
As Graph 11a shows, the results for the Polish speakers are similar to those of the German speakers in experiment 2: the longest friction in Polish is attested when $/ \mathrm{t} /$ and $/ \mathrm{d} /$ are preceded by $\mathrm{a}_{-}$. When the stops are preceded by $\mathrm{i}_{-}$the friction is shorter and when preceded by $u_{-}$the friction is the shortest. Not all differences are statistically significant. In $/ \mathrm{t} /$ sequences the context $a_{-}$vs. $i_{-}$is not significant, while $u_{-}$vs. $i_{-}$is significant $(F(2,624)=13.583, p<.01)$ and $a_{-}$ vs. $u_{-}$is highly significant $(\mathrm{p}<.001)$. As far as $/ \mathrm{d} /$ sequences are concerned only

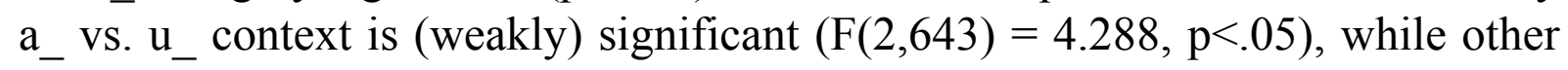
contexts are not significant. Taking /t/ and /d/ sequences together, cf. Graph $11 \mathrm{~b}$, the $a_{-}$vs. $u_{-}$context is highly significant $(F(2,1268)=9.308, p<.001)$ and $u_{-}$ vs. $i_{-}$is weakly significant $(p<.05)$. The difference in the a_vs. $i_{-}$context is not significant. Possible explanations for the influence of the preceding vowel on friction duration are discussed in section 6.4.

Finally, the influence of stress on the friction duration was investigated, cf. (8c). Graphs 12a and 12b show the friction length in German as influenced by stress. Note that Ax denotes a bisyllabic item with initial stress, and xA a bisyllabic item with final stress.

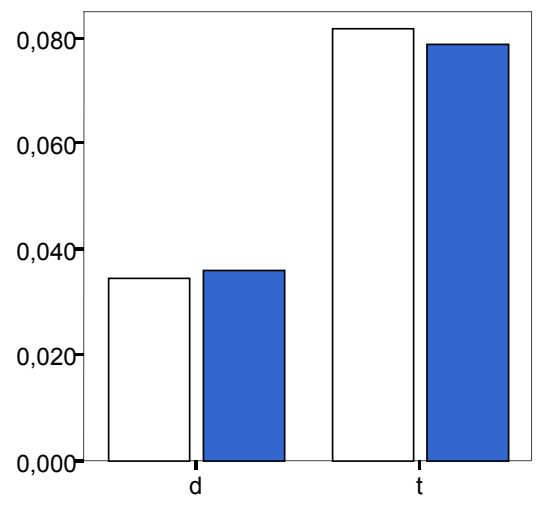

$a$

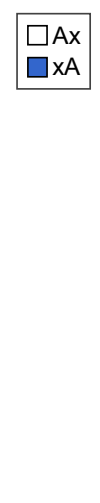

$\square \mathrm{Ax}$
$\square \mathrm{xA}$

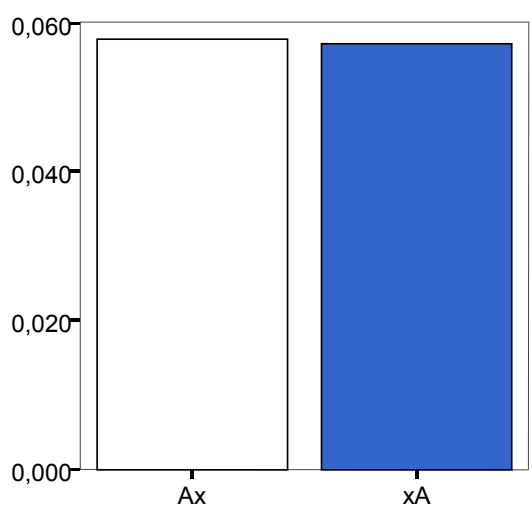

b

Graph 12: The average duration of friction in s dependent on stress for $/ \mathrm{dj} /$ and $/ \mathrm{tj} / \mathrm{separately}$ (a) and for $/ \mathrm{tj} /$ and $/ \mathrm{dj} /$ together (b). German speakers.

The results in Graphs 12a and 12b show that stress does not have a considerable influence on the friction duration in German. If / t $\mathrm{j} /$ and /ti/ occur in a prestressed position, the friction duration is slightly longer than when they occur in a stressed position. The opposite is true for / dj/ and /di/ sequences, cf. Graph 12a. None of the differences is statistically significant. Graph $12 \mathrm{~b}$ confirms that there is almost no difference in friction duration when the tested items are evaluated together.

Polish speakers performed differently with respect to the influence of stress. The results are depicted in Graphs 13a and $13 \mathrm{~b}$. 


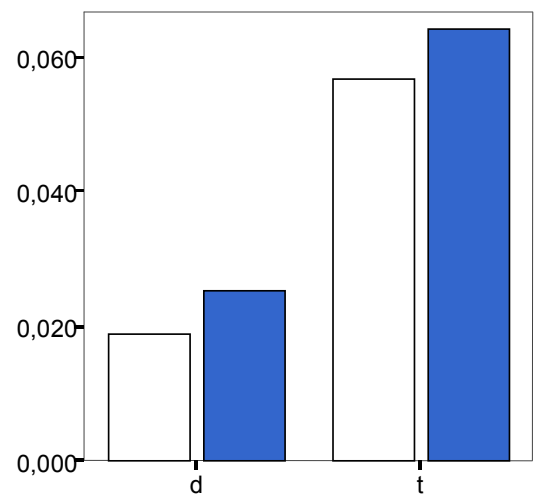

$a$
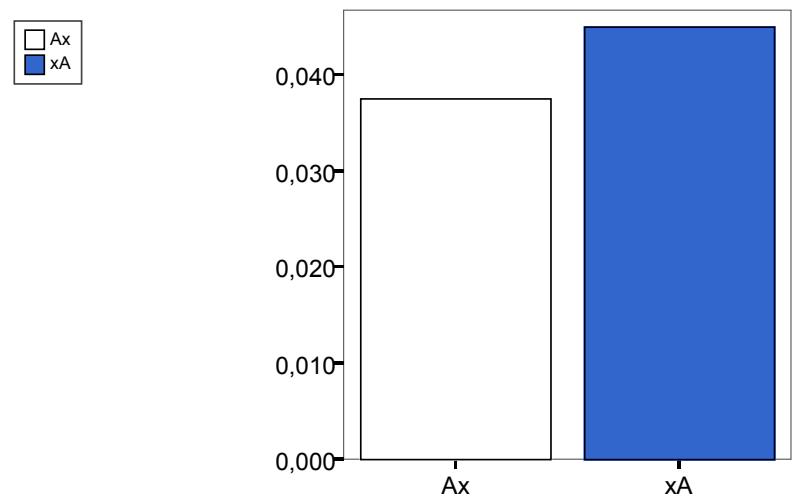

b

Graph 13: The average duration of friction in s dependent on stress for $/ \mathrm{dj} /$ and $/ \mathrm{tj} /$ separately (a) and for $/ \mathrm{tj} /$ and $/ \mathrm{dj} /$ together (b). Polish speakers.

The differences in friction duration for $/ \mathrm{d} / \mathrm{and} / \mathrm{t} /$ presented in Graph 13a are statistically highly significant (for $/ \mathrm{d} / \mathrm{F}(1,643)=15.254, \mathrm{p}<.001$ and for $/ \mathrm{t} /$ $\mathrm{F}(1,624)=16.590 \mathrm{p}<.001)$ showing that in Polish the friction duration is longer in a stressed than in a prestressed position for both $/ \mathrm{t} /$ and $/ \mathrm{d} /$ sequences. A similar result is obtained by calculating the friction duration without splitting the data: a longer friction is attested in a stressed than in a prestressed position $(\mathrm{F}(1,1268)=20.928, \mathrm{p}<.001)$, cf. Graph 13b. Section 6.3 will give possible explanations for this language-specific dependence of friction duration on stress.

\section{$5 \quad$ Findings}

In addition to supporting the four predictions in (6) and the assibilation hierarchy in (7), the three experiments described in the previous section led to several findings not discussed in the literature on assibilations. In this section we summarize these findings.

One finding supported by our experiments which was not made by Hall \& Hamann (2003) or in any earlier study to our knowledge is stated in (9):

(9) The friction phase in $/ \mathrm{dj} /$ is shorter durationally than in $/ \mathrm{ti} /$.

The finding in (9) suggests that the assibilation hierarchy presented above in (7) should be modified as in (10):

(10) An assibilation hierarchy:

$/ \mathrm{tj} /</ \mathrm{ti} /</ \mathrm{dj} /</ \mathrm{di} /$ 
If the hierarchy in (10) is truly universal then one would expect it to be reflected in a typology like the one summarized above in (4). For example, one should be able to find evidence for an implication of the form "if /d/ assibilates before / $\mathrm{j} /$ then $/ \mathrm{t} /$ assibilates before $/ \mathrm{i} /$ ". This is clearly a question we leave open for further research.

Three additional results of the three experiments conducted are summarized in (11):

(11) Three additional results:

a. The vowel following $/ \mathrm{tj} /$ and $/ \mathrm{dj} /$ influences the friction phase in the sense that $/ \mathrm{i} /$ results in a longer friction phase than $/ \mathrm{u} /$ or $/ \mathrm{a} /$;

b. The vowel preceding $/ \mathrm{tj} /$ etc. influences the friction phase in the sense that $/ a /$ results in a longer friction phase than $/ \mathrm{i} /$ or $/ \mathrm{u} /$;

c. Stress of the vowels adjacent to $/ \mathrm{t} j /$ etc. does not influence the duration of the friction phase in German but it does in Polish in the sense that there is a longer friction phase if the stress follows the $/ \mathrm{tj} \mathrm{dj} /$ sequence.

Again, results like the ones in (11) can be (dis)confirmed by considering phonological assibilation rules from the typological perspective.

\section{Discussion}

In this section, possible explanations for the attested differences in friction length are discussed. Section 6.1 focusses on the difference in outcome for $/ \mathrm{i} /$ versus $/ \mathrm{j} /$, section 6.2 on the difference for $/ \mathrm{d} /$ versus $/ \mathrm{t} /$, section 6.3 on the influence of stress, and section 6.4 on the influence of the quality of the preceding and following vowel.

\subsection{The distinction between /i/ and /j/}

All three acoustic experiments show that a coronal stop (be it voiceless or voiced) followed by a palatal glide $/ \mathrm{j} /$ has a longer total friction phase than a coronal stop followed by the vowel /i/. Three possible explanations for these results can be offered, two articulatory and one aerodynamic.

The first explanation is based on the articulatory difference between the vowel $/ \mathrm{i} /$ and the glide $/ \mathrm{j} /$ : the palatal glide might be articulated with a narrower constriction, which then causes greater impedance to the escaping air and thus a longer friction phase, cf. Klatt (1975) and Ohala (1983). Data on the articulatory difference between palatal glide and high front vowel to attest this point are scarce. In Figure 5 we have provided an x-ray tracing for $/ \mathrm{i} /$ and $/ \mathrm{j} /$ from one native speaker of Polish (from Wierzchowska 1971). 

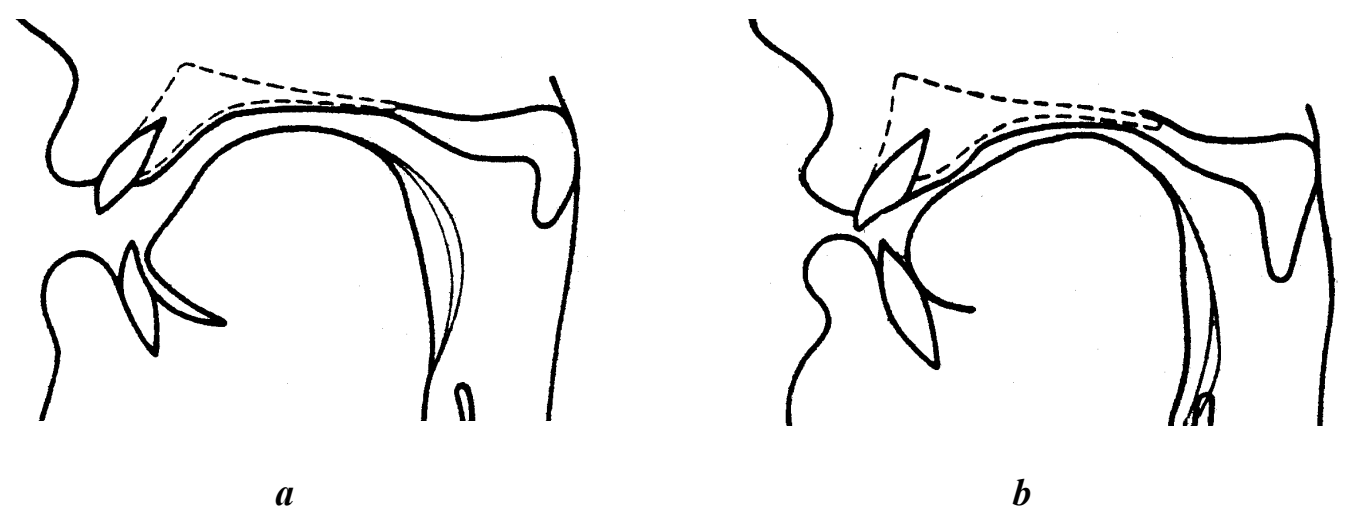

Figure 5: X-ray tracings for (a) /i/ and (b) /j/ in Polish. The thin lines at the back of the tongue indicate the lateral tongue positions.

A comparison of the tongue body in $/ \mathrm{i} / \mathrm{vs} . \mathrm{j} /$ reveals an obvious difference between the two: For the latter sound the constriction is longer and narrower than for $/ \mathrm{i} /$.

The difference in degree and length of constriction between $/ \mathrm{i} /$ and $/ \mathrm{j} /$ for the Polish speaker in Figure 5 is also assumed for the languages investigated by Maddieson and Emmorey (1985). They compared the formant frequencies of the palatal glide and the high front vowel in Amharic, Yoruba, and Zuni and found that in all three languages the glide has a lower first formant frequency than the vowel. Their conclusion is that the glide $/ \mathrm{j} /$ is produced with a narrower constriction than the vowel $/ \mathrm{i} / .^{5}$

In other languages the difference in length and degree of constriction is not as obvious as in Polish. For example, Wängler's (1961) x-ray tracings of German $/ \mathrm{i} / \mathrm{and} / \mathrm{j} /$ for one speaker show that the two segments are articulated almost identically.

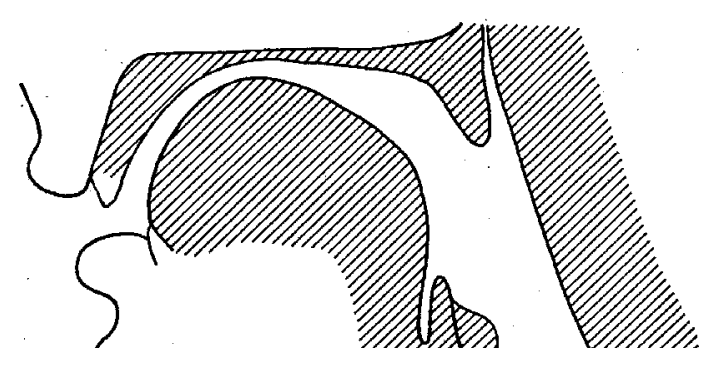

$a$

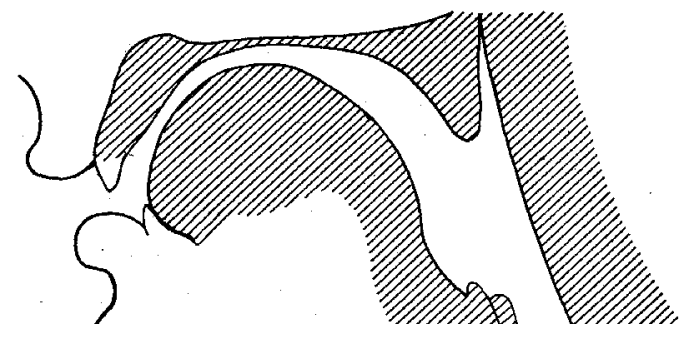

$\boldsymbol{b}$

Figure 6: X-ray tracings for (a) /ii: and (b) /j/ in German.

5 The recordings leading to this result only include tokens of /i/ in palatal glide context (in the nonsense word $i j i$ ). However, the glide in this sequence might be articulated with a closer constriction than in other vocalic contexts in order to maintain a perceptual difference between glide and vowel. 
A comparison of Figure $6 \mathrm{a}$ with $6 \mathrm{~b}$ reveals that the palatal glide $/ \mathrm{j} /$ has a minimally longer constriction, i.e. the tongue front is raised a bit further than for the $/ \mathrm{i} /$. At this point one can only speculate that this minor difference between length of constriction between $/ \mathrm{i} / \mathrm{h}$ and $/ \mathrm{j} / \mathrm{might}$ be responsible for the longer duration of the friction phase in $/ \mathrm{tj} \mathrm{dj} / \mathrm{vs}$. $/ \mathrm{ti} \mathrm{di} /$.

Like German, Romanian does not seem to support an articulatory difference between glide and vowel, either. Chitoran $(2002,2003)$ investigated the phonetic difference between the high front vowel $/ \mathrm{i} /$ and the glide $/ \mathrm{j} /$ in Romanian, and measured their friction duration after the stop $/ \mathrm{p} /,^{6}$ and the formant values at the starting point of both segments. The duration of the friction phase was expected to be longer for the glide, indicating a narrower constriction. However, no significant differences could be found. Furthermore, Chitoran expected significant differences in the formant values at the beginning of the two segments. She found - contrary to what one would expect if $/ j /$ has a narrower constriction than $/ \mathrm{i} / \mathrm{-}$ that the second formant was higher in the vowel for two of her three speakers. Chitoran (2003:3016) interprets the lower F2 values for the glides as a 'target undershoot', which means that the glide is articulated with even less constriction than the vowel in the same context.

The results of these cross-linguistic studies might indicate a languagespecific difference between the glide $/ \mathrm{j} /$ and the vowel $/ \mathrm{i} /$ : In German, the two seem to be articulated similarly, in Romanian the glide $/ \mathrm{j} /$ seems to be articulated with a less narrow constriction than the vowel /i/, and in Amharic, Yoruba, Zuni and Polish the glide seems to have a more narrow constriction. However, it has to be kept in mind that these are mostly the interpretations of acoustic studies and that neither Chitoran, nor Maddieson and Emmorey, nor the present authors conducted articulatory studies on the difference between /i/ vs. /j/ to test these interpretations. $^{7}$

A second explanation for the difference in friction length between glide and vowel could be the influence of the glide on the preceding stop. As B. Hurch (p.c.) pointed out to us, the glide can cause an inherent palatalization of the preceding stop: the stop before the glide is articulated with a raised tongue

6 Chitoran's definition of friction duration differs from the one applied in the present article: it is the duration measured from the end of the [p] release burst to the onset of F1 (Chitoran 2003: 3014).

7 The cross-linguistic difference between high front vowel and the corresponding glide might be based on the fact that languages differ in their realization of the vowel [i], as P. Boersma (p.c.) pointed out to us. Thus, a very high [i] as it is the case in German might result in little articulatory difference between vowel and glide, whereas a lower [i] as we assume to be the case in Polish might result in a bigger articulatory difference between vowel and glide. We have at present no comparative data from German, Polish or any other language which might support this hypothesis. 
middle, which can, due to a longer constriction, result in more friction than the non-palatalized stop before the high front vowel. The stop before the high front vowel, on the other hand, does not show this inherent palatalization. Like the first articulatory proposal, this explanation still has to be tested.

The third and final explanation proposed here is not based on articulation but on aerodynamics (see also the authors referred to in note 1). It could be argued that the glide is produced with stronger airflow than the vowel, and that the higher airflow results in longer friction noise following the release of the stop. We are currently testing this hypothesis (Hall, Hamann \& Zygis in prep.), and preliminary results show that the $/ \mathrm{j} /$ following coronal stops has stronger airflow than the $/ \mathrm{i} /$ in the same context (results from two German speakers).

\subsection{The distinction between /t/ and /d/}

The voiced stops / $\mathrm{di} \mathrm{dj} /$ generally show a shorter friction duration than the corresponding voiceless stops $/ \mathrm{ti} \mathrm{tj} /$. One reason for this observation is that whereas the open vocal folds for a voiceless stop allow air to pass unimpeded, the vibrating vocal cords of the voiced stop restrict the air flow volume. This results in less air pressure behind the alveolar constriction for voiced stops and thus less friction noise at the release of the voiced stop. Furthermore, the voicing of stops requires a difference between subglottal and supraglottal pressure (in order to let the vocal folds vibrate), which is usually maintained by pharyngeal expansion and larynx lowering (Kent \& Moll 1969, Perkell 1969, Bell-Berti 1975). Pharyngeal expansion also results in less air pressure at the constriction and less friction at the stop release (Ohala \& Riordan 1979). The higher subglottal pressure and lower intraoral air pressure for voiced stops compared to voiceless stops has been attested by Netsell (1969) for American English.

Another factor to consider is a possible difference in articulation between the voiced and the voiceless stop. If / $t /$ is a laminal sound and $/ \mathrm{d} /$ an apical (as in some West-African languages, see Ladefoged 1964) ${ }^{8}$, then one might expect the former to assibilate, as apicals should be less prone to assibilation than laminals due to their smaller oral closure. Since the two experiments described in section 4 were acoustic and not articulatory, we do not know if the subjects had a distinction between laminal vs. apical $/ \mathrm{t} \mathrm{d} /$. However, this hypothesis it testable in an articulatory experiment.

8 The difference between tongue tip and tongue blade reported by Ladefoged (1964) goes together with a difference in place of articulation, with apicals being articulated in the (post-) alveolar area, and laminals in the dental area. 


\subsection{The influence of stress}

Stress was shown to be an influencing factor on friction duration in Polish but not in German, as shown in Graphs 12 and 13: the stressed stops in Polish had significantly longer friction than the unstressed ones. This language-specific difference might be due to the realization of stress in Polish versus German. To account for our data, Polish should have a more enforced articulation of the stop in stressed position than in unstressed position, whereas German should not show such a difference. At present, we do not have comparative data on German and Polish to support this hypothesis.

\subsection{The quality of adjacent vowels}

The vowel preceding /ti/ etc. was another factor demonstrated in our experiments to influence the friction phase. Graphs 10 and 11 showed that a preceding /a/ yields longest friction duration, whereas preceding / $\mathrm{u} /$ and /i/ differ only slightly in their influence on the friction.

Although this point requires a detailed articulatory and aerodynamic investigation, we think that the longest friction in the case of the preceding /a/ may be influenced by its largest oral cavity (the tongue body is flat) and consequently by the largest air volume in comparison to $/ \mathrm{u} /$ and $/ \mathrm{i} /$ where the tongue body is in a higher position. The largest air volume needs the longest time to pass the supraglottal constriction and thus results in the longest friction. Unfortunately, we are not aware of any study dealing with this issue.

The final parameter to account for is the influence of the vowel following stop plus $/ \mathrm{j} /$ sequences. In section 4.2 we saw that the friction duration of a stop is considerably longer if an /i/ follows compared to a following /a/ (see Graphs 8 and 9). The influence of the following / $\mathrm{i} / \mathrm{can}$ be ascribed to the fact that languages generally avoid [ji] (and [wu]) sequences for perceptual reasons, as a number of studies on typologically diverse languages have shown (see, for example Kawasaki 1982). If [ji] sequences occur in a language, the glide seems to be articulated with a higher tongue position than in other glide vowel sequences. ${ }^{9}$ This higher tongue position then causes longer friction at the release of the stop into the glide, resulting in a longer friction duration observed in our second experiment. The raising of the tongue position for the glide can be argued to be a gradual process, dependent on the quality of the following vowel. This is attested by the fact that a following $/ \mathrm{u} /$ results in longer friction phase

9 Evidence for this assumption is given by Laver (1994:298), who remarks that the articulatory starting point for [j] in $j i$ sequences of English and the Chentu dialect of Chinese is normally slightly closer and fronter than for [i]. 
than a following /a/ (this difference was shown to be significant for German but not for Polish): $/ \mathrm{u} /$ is also articulated with a high tongue body, requiring an adjacent glide with a high tongue body position. These hypotheses on the influence of the following vowel on stop-glide sequences could in principle be tested articulatorily.

\section{$7 \quad$ Alternative explanation: Center of gravity}

In the preceding sections we only considered friction duration as an explanation for the assibilation hierarchy in (10) and the implications in (5) - repeated in (12) and (13) for convenience:

(12) An assibilation hierarchy $/ \mathrm{tj} /</ \mathrm{ti} /</ \mathrm{dj} /</ \mathrm{di} /$

(13) Two implications:

a. Assibilation cannot be triggered by $/ \mathrm{i} /$ unless it is also triggered by $/ \mathrm{j} /$.

b. Voiced stops cannot undergo assibilations unless voiceless ones do.

The assibilation hierarchy in (12) might also be attributable to other acoustic factors, such as the spectral similarities between the friction of the alveolar fricative part of affricates like /ts dz/ and the friction before $/ \mathrm{i} \mathrm{j} /$ in sequences like / ti t $\mathrm{j} \mathrm{di} \mathrm{dj} /$. The assibilation hierarchy in (12) would therefore be supported if the friction in $/ \mathrm{s} \mathrm{z} /$ were spectrally more similar to the friction in $/ \mathrm{tj} /$ than the one in $/ \mathrm{ti} \mathrm{dj} /$, and more similar to the friction in $/ \mathrm{ti} \mathrm{dj} /$ than in $/ \mathrm{di} /$.

In order to test this alternative explanation we conducted an additional pilot study in which we measured the center of gravity (henceforth: COG) (cf. Jassem 1979, Nittrouer, Studdert-Kennedy \& McGowan 1989, Forrest et al. 1998, Jongman, Wayland \& Wong 2000, Gordon, Barthmaier \& Sands 2002). $\mathrm{COG}$ is the average of frequencies over the entire frequency domain weighted by the amplitude. In our measurements, the weighting was done by using the power spectrum $(p=2)$ in PRAAT. For the COG calculations we excluded the burst (ca. $10 \mathrm{~ms}$ ) and measured the friction up to the beginning of continuous formants. To exclude the influence of the fundamental frequency in the voiced items, we band pass filtered all signals with a pass Hann band of 500-12000 $\mathrm{Hz}$ (and a smoothing of $100 \mathrm{~Hz}$ ).

COG values were measured for the items in Table 3 spoken by two German speakers (female SH and male JD) and two Polish speakers (female MZ and male SL). The items were repeated five times in the same carrier sentences as used in section 4.2 above.

The results for the German speakers are presented in Graph 14. 

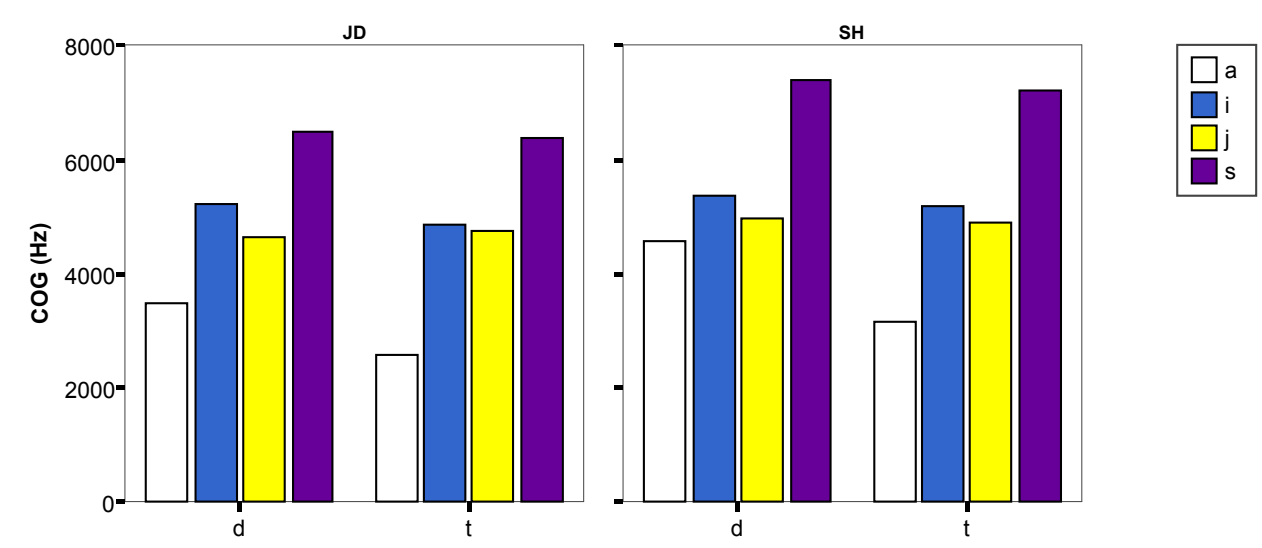

Graph 14: The average COG in $\mathrm{Hz}$ for the two German speakers. The context of the following 's' includes the fricative part of the alveolar affricates in $t s i k$ and $d z i k$.

Both German speakers show an ordering of the COG values for items like the ones in (14), where the wedge ' $<$ ' means 'has a lower COG value than'; hence, /tak/ has a lower COG value than/tjak/, etc.

$$
\begin{aligned}
\text { (14) } \text { tak } & <\text { tjak }(<) \text { tik }<\text { tsik } \\
\text { dak } & <\text { djak }(<) \text { dik }<\text { dzik }
\end{aligned}
$$

The wedges between tjak and tik and between djak and dik are in brackets, because a post-hoc Scheffé test shows that for both speakers the difference between $/ \mathrm{i} /$ and $/ \mathrm{j} /$ for both $/ \mathrm{t} / \mathrm{and} / \mathrm{d} /$ is not significant. For speaker $\mathrm{SH}$ the difference between $/ \mathrm{da} /$ and $/ \mathrm{dj} /$ is also not significant. All other differences are significant (For JD /da/ vs. $/ \mathrm{di} / \mathrm{p}<.01, / \mathrm{da} / \mathrm{vs} . / \mathrm{dj} / \mathrm{p}<.05, / \mathrm{da} / \mathrm{vs} . / \mathrm{dz} / \mathrm{p}<.001$, /di/ vs. $/ \mathrm{dz} / \mathrm{p}<.05, / \mathrm{dj} /$ vs. $/ \mathrm{dz} / \mathrm{p}<.01$. For $\mathrm{SH} / \mathrm{da} /$ vs. $/ \mathrm{di} / \mathrm{p}<.01, / \mathrm{da} / \mathrm{vs} . / \mathrm{dz} /$ $\mathrm{p}<.001, / \mathrm{di} / \mathrm{vs} . / \mathrm{dz} / \mathrm{p}<.001, / \mathrm{dj} / \mathrm{vs} . / \mathrm{dz} / \mathrm{p}<.001$. All remaining differences for $/ \mathrm{t} /$ for both speakers are highly significant $\mathrm{p}<.001$ ).

The results for the Polish speakers are given in Graph 15.
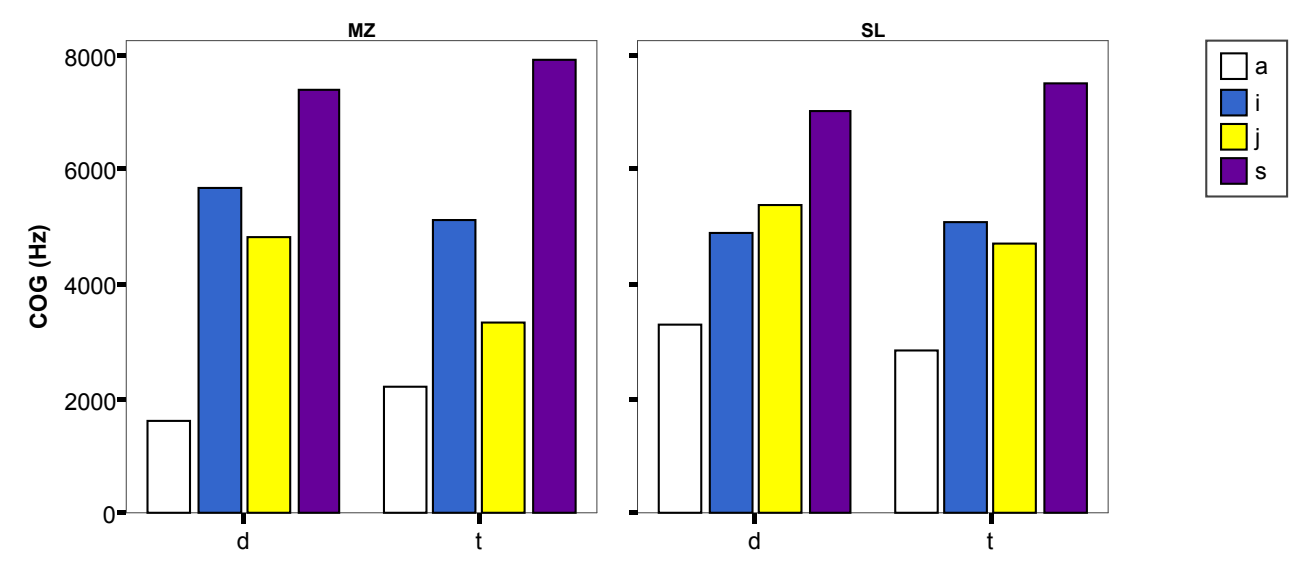

Graph 15: The average COG in Hz for the two Polish speakers. The context 's' includes the fricative part of the alveolar affricates in $t s i k$ and $d z i k$. 
The ordering of the items for the Polish speakers according to their COG values is similar to the German speakers in (14), with the only exception being that speaker SL has a reverse ordering for $/ \mathrm{di} /$ and $/ \mathrm{dj} /$. The difference between $/ \mathrm{di} /$ and $/ \mathrm{dj} /$ is not significant for either speaker. For speaker SL the difference between $/ \mathrm{ti} /$ and $/ \mathrm{tj} /$ is also not significant, whereas for speaker $\mathrm{MZ}$ this difference is highly significant. All other differences are significant (for $\mathrm{MZ} / \mathrm{di} /$ vs. $/ \mathrm{dz} / \mathrm{p}<.05, / \mathrm{dj} / \mathrm{vs} . / \mathrm{dz} / \mathrm{p}<.01$, all other differences with $/ \mathrm{d} /$ are $\mathrm{p}<.001 ; / \mathrm{ta} /$ vs. $/ \mathrm{t} j /$ is significant $\mathrm{p}<.01$, all other differences with $/ \mathrm{t} /$ are highly significant. For SL $/ \mathrm{da} / \mathrm{vs}$. $/ \mathrm{di} / \mathrm{p}<.005, / \mathrm{da} / \mathrm{vs} . / \mathrm{dj} / \mathrm{p}<01, / \mathrm{di} / \mathrm{vs} . / \mathrm{dz} / \mathrm{p}<.01, / \mathrm{dj} / \mathrm{vs} . / \mathrm{dz} /$ $\mathrm{p}<.01, / \mathrm{da} / \mathrm{vs} . / \mathrm{dz} /$ highly significant; for $/ \mathrm{t} /$ all differences apart from $/ \mathrm{ti} / \mathrm{vs}$. $/ \mathrm{tj} /$ are highly significant).

The COG values for all four speakers thus show that sequences of coronal stop plus $/ \mathrm{i} \mathrm{j} /$ are more similar to the respective coronal fricatives $/ \mathrm{s} \mathrm{z} /$ than sequences of coronal stop plus $/ \mathrm{a} /$. This finding points to a reason that assibilation is triggered by high front vowels but not by low vowels. However, an explanation for implication (13a) could not be found in the COG values. The reason is that none of the speakers has a significant difference in COG values between /i/ and /j/ items (apart from speaker $M Z$ whose /ti/ items have significantly higher COG values than the / $\mathrm{tj} / \mathrm{items}$ ) and the ordering between $/ \mathrm{i}$ / and $/ \mathrm{j} /$ is actually reverse from the expected.

Were the results of these COG measurements to support implication (13b), we expect to find a greater difference in COG values between $/ \mathrm{di} \mathrm{dj} /$ and $/ \mathrm{dz} /$ than between $/ \mathrm{ti} \mathrm{tj} /$ and $/ \mathrm{ts} /$. For these calculations we measured the COG values of the fricatives including the fundamental frequency (i.e., no band pass filtering as in the COG measurements above was conducted). The results for the German speakers are given in Graph 16. COG mean values of /di/ were subtracted from COG mean values of /dz/, which is shown in the first column on the left; the second column shows the difference in the COG mean values of $/ \mathrm{dz} /$ and $/ \mathrm{dj} /$. In a parallel manner the differences for voiceless stops are shown by the columns on the right. 

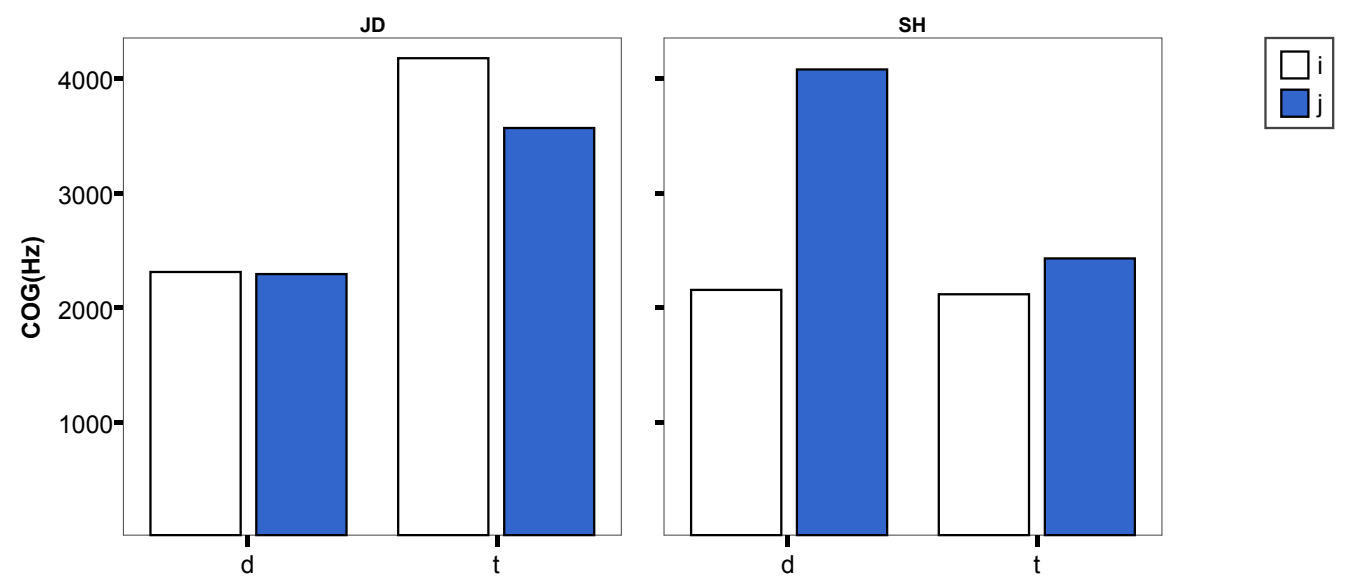

Graph 16: The average difference in COG in $\mathrm{Hz}$ for the two German speakers.

For speaker JD, the value /dz/ - /di/ (first column) is smaller than that for /ts/ $/ \mathrm{ti} /$ (third column), and $/ \mathrm{dz} /-/ \mathrm{dj} /$ (second column) is smaller than $/ \mathrm{ts} /-/ \mathrm{tj} /$ (fourth column). This finding is important because it does not support the expected result that differences for the voiced stop are larger than the voiceless stops. A different picture arises for speaker $\mathrm{SH}$, for whom $/ \mathrm{dz} / \mathrm{-} / \mathrm{di} /$ is almost identical to $/ \mathrm{ts} /$ - /ti $/$, and $/ \mathrm{dz} /$ - / $\mathrm{dj} /$ is greater than $/ \mathrm{ts} /$ - $/ \mathrm{tj} /$.

The differences in COG values between the affricate and $/ \mathrm{i} j /$ for the Polish speakers are given in Graph 17, again for the voiced stops on the left and the voiceless stops on the right.
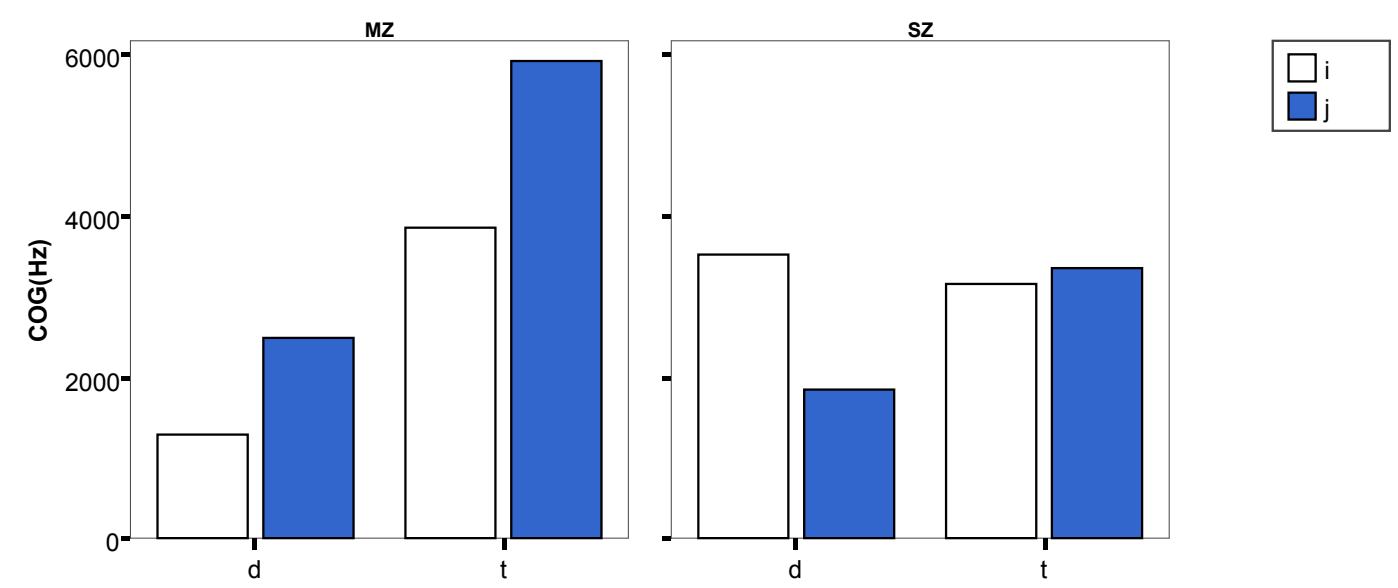

Graph 17: The average difference in COG in $\mathrm{Hz}$ for the two Polish speakers.

Speaker MZ shows a larger value for both voiceless alveolar stops than for the voiced alveolar stops, and speaker SZ has a larger value for $/ \mathrm{dz} /-/ \mathrm{di} /$ than for $/ \mathrm{ts} /$ - /ti /, but a smaller value for $/ \mathrm{dz} /$ - $/ \mathrm{dj} /$ than for $/ \mathrm{ts} /-/ \mathrm{tj} /$. The results of both German and Polish speakers are so diverse that a statistical analysis is unnecessary. In sum, there is no general tendency that the difference in COG values for voiced stops is greater than the difference between voiceless stops, and therefore no evidence for implication (13b). 
Summing up this section, the results of the COG measurements can account for the fact that assibilation takes place before high front vocoids and not before low vowels, but they do not provide evidence for the assibilation hierarchy in (12) or for the implications in (13).

\section{Conclusion}

In this article we reported on the results of three acoustical experiments in which the duration of the friction phase of / $\mathrm{ti} \mathrm{di} \mathrm{tj} \mathrm{dj} /$ were measured in German and Polish and showed the relevance of these experiments to language typology. The results indicate that the friction phase for these four sequences can be arranged in the order $/ \mathrm{tj} /</ \mathrm{ti} /</ \mathrm{dj} /</ \mathrm{di} /$, meaning that the friction phase in $/ \mathrm{tj} /$ is longer than in /ti/ etc. The results of these experiments are important because they lend phonetic support to two proposed implications with respect to phonological stop assibilation which were made in an earlier study (Hall \& Hamann 2003), namely (a) assibilation cannot be triggered by /i/ unless it is also triggered by $/ \mathrm{j} /$, and (b) voiced stops cannot undergo assibilations unless voiceless ones do.

The additional COG measurements showed that this parameter does not provide evidence for the assibilation hierarchy $/ \mathrm{tj} /</ \mathrm{ti} /</ \mathrm{dj} /</ \mathrm{di} /$. However, further investigations into the spectral shape of the friction phase in the sequences $/ \mathrm{tj} \mathrm{ti} \mathrm{dj} \mathrm{di} /$ and the fricative component of $/ \mathrm{dz}$ ts/ could account for the observed ordering among alveolar stop plus high vocoid sequences.

\section{References}

Bell-Berti, F. 1975. Control of pharyngeal cavity size for English voiced and voiceless stops. Journal of the Acoustical Society of America 57: 456-461.

Bhat, D. N. S. 1978. A general study of palatalisation. In: J. Greenberg et al. (eds.), Universals of Human Language, 47-92. Stanford: Stanford University Press.

Byrd, D. (1993). 54,000 stops. UCLA Working Papers in Phonetics 83, 97-115.

Cedegren, H. J., J. D. Archambault \& G. Boulianne 1991. Stop assibilation in Quebec French: an analysis by articulatory synthesis. Proceedings of the $12^{\text {th }}$ International Congress of Phonetic Sciences. Vol. 3. Aix-en-Provence. 186-189.

Chitoran, I. 2002. A perception-production study of Romanian diphthongs and glide-vowel sequences. Journal of the International Phonetic Association 32,2: 203-222.

Chitoran, I. 2003. Gestural Timing and the Glide Percept in Romanian. Proceedings of the 15th International Congress of Phonetic Sciences: 3013-3016.

Clements, G. N. 1999. Affricates as noncontoured stops. In: O. Fujimura et al. (eds.), Item, Order in Language and Speech, 271-299. Prague: Charles University Press.

Dougherty, J. W. D. 1983. West Futuna-Aniwa: An Introduction to a Polynesian Outlier Language. Berkeley: University of California Press. 
Foley, J. 1973. Assibilation as universal phonological rule. Folia Linguistica 6 (3-4): 251262.

Foley, J. 1977. Foundations of Theoretical Phonology. Cambridge: Cambridge University Press.

Forrest, K., Weismar, G. Milenkovic, P. \& R. N. Dougall. 1988. Statistical analysis of wordinitial voiceless obstruents: Preliminary data. Journal of the Acoustical Society of America 84, 115-124.

Gordon, M., Barthmaier, P. and K. Sands. 2002. A cross-linguistic acoustic study of voiceless frictives. Journal of the International Phonetic Associtation 32, 141-171.

Hall, T.A. \& S. Hamann. 2003. Towards a typology of stop assibilation. In: T.A. Hall \& S. Hamann (eds.) Papers on Phonetics and Phonology. ZAS Papers in Linguistics 32: 111-136.

Hall, T.A., S. Hamann, \& M. Zygis. In prep. The aerodynamics of stop assibilation. Ms. ZAS Berlin.

Hanson, M.H. \& K.N. Stevens. 2003. Models of aspirated stops in English. Proceedings of the $15^{\text {th }}$ ICPhS, Barcelona. 783-786.

Jäger, J. 1978. Speech Aerodynamics and Phonological Universals. Berkeley: Proceedings of the $4^{\text {th }}$ Annual Meeting of the Berkeley Linguistics Society. Berkeley Linguistics Society. 311-329.

Jassem, W. 1979. Classification of fricative spectra using statistical discriminant functions. In: Lindblom B. \& S. Öhman (eds.) Frontiers of Speech Communication Research. New York: Academic Press.

Jessen, M. \& C. Ringen 2002. Laryngeal features in German. Phonology 19: 189-218.

Jongman, A., Wayland, R. \& S. Wong. 2000. Acoustic characteristics of English fricatives. Journal of the Acoustical Society of America 108, 1252-1263.

Kawasaki. 1982. An Acoustical Basis for Universal Constraints on Sound sequences. Ph.D. dissertation. University of California at Berkeley.

Kent, R. D. \& K. L. Moll. 1969. Vocal-tract characteristics of the stop cognates. Journal of the Acoustical Society of America 46: 1549-1555.

Kim, H. 2001. A phonetically based account of phonological stop assibilation. Phonology 18, 81-108.

Kiparsky, P. 1973. Abstractness, opacity and global rules. In: O. Fujimura (ed.), Three Dimensions of Linguistic Theory, 57-86. Tokio: Taikusha.

Klatt, D. 1975. Voice onset time, frication and aspiration in word-initial consonant clusters. Journal of Speech and Hearing Research 18: 686-706.

Kohler, K. 1995. Einführung in die Phonetik des Deutschen. Berlin: Erich Schmidt Verlag.

Ladefoged, P. 1964. A Phonetic Study of West African Languages: An Auditory-Instrumental Survey. Cambridge: Cambridge University Press.

Laver, J. 1994. Principles of Phonetics. Cambridge: Cambridge University Press.

Liberman, A.M., Delattre, P. C. and F. S. Cooper (1958). Some cues for the distinction between voiced and voiceless stops in initial position. Language \& Speech 1, 153-167.

Lisker, L \& A.S. Abramson (1964). A cross-language study of voicing in initial stops: Acoustical measurements. Word 20: 384-422.

Maddieson, I. \& Emmorey, K. 1985. Relationship between semivowels and vowels: crosslinguistic investigations of acoustic difference and coarticulation. Phonetica 42: 163174. 
Matisoff, J. A. 1982. The Grammar of Lahu. Berkeley: University of California Press.

Netsell, R. 1969. Subglottal and Intraoral Air Pressures during the Intervocalic Contrast of /t/ and /d/. Phonetica 20: 68-73.

Nittrouer, S., Studdert-Kennedy, M and R.S. McGowan. 1989. The emergence of phonetic segments: evidence from the spectral structure of fricative-vowel syllables spoken by children and adults. Journal of Speech and Hearing Research 32, 120-132.

Ohala, J. 1983. The origin of sound patterns in vocal tract constraints. In: P. MacNeilage (ed.), The Production of Speech, 189-216. New York: Springer.

Ohala, John J. \& C. J. Riordan. 1979. Passive vocal tract enlargement during voiced stops. In: J. J. Wolf \& D. H. Klatt (eds.) Speech Communication Papers, New York: Acoustical Society of America; 89-92.

Perkell, J. S. 1969. Physiology of Speech Production: Results and Implications of a Quantitative Cineradiographic Study. Cambridge: MIT Press.

Pope, M. K. 1952. From Latin to Modern French with special consideration of AngloNorman. Phonology and Morphology. Manchester: Manchester University Press.

Stevens, N. K. 1998. Acoustic Phonetics. Cambridge, Mass./London, England: the MIT Press.

Stevens, K. N., Manuel, S. Y. \& M. Matthies. 1999. Revisiting place of articulation measures for stop consonants: implications for models of consonant production. Proceedings of $14^{\text {th }}$ ICPhS, San Francisco. 1117-1120.

Wängler, H. H. 1961. Atlas deutscher Sprachlaute. Berlin: Akademie Verlag.

Wierzchowska, B. 1971. Wymowa Polska. Warzawa: Państwowe Zakłady Wydawnictw Szkolnych.

Wierzchowska, B. 1980. Fonetyka i fonologia języka polskiego. Warszawa: Zakład Narodowy im. Ossolińskich: Wydawnictwo Polskiej Akademii Nauk.

Wiese, R. 1996. The Phonology of German. Oxford: Clarendon Press. 